\begin{abstract}
高结晶性小分子给体材料应用于 全小分子有机太阳能电池中的研究进展

\author{
吕敏 $a, b$ 周瑞敏 $a, b$ 吕琨 $*, a, b$ 魏志祥 $a, b$ \\ ( $a$ 中国科学院纳米系统与多级次制造重点实验室 中国科学院纳米科学卓越中心 国家纳米科学中心 北京 100190) \\ ( ${ }^{b}$ 中国科学院大学 北京 100049)
}

摘要 随着新型小分子给体材料和非富勒烯小分子受体材料的开发和应用, 非富勒烯全小分子有机太阳能电池 (NF-ASM OSCs) 的光电转换效率已经突破 $15 \%$, 并逐渐接近聚合物太阳能电池的效率. 相比于聚合物电子给体材料, 小分子电子给体材料拥有其独特的优势, 例如合成批次性差异小、分子量明确和易于提纯等; 但是, 对小分子给体材 料的结晶性难于精确调控, 使获得合适的纳米级结构的混合膜仍然是一个挑战. 本综述以给体小分子中心共轭单元的 扩展为主线, 从分子设计的角度汇总了近年来对苯并二噻吩、萗并二噻吩和二噻并苯并二噻吩类小分子给体材料的结 晶性研究, 并为进一步改善电池活性层形貌和获得更高的光伏性能提供了未来发展的建议.
\end{abstract}

关键词＼cjkstart全小分子有机太阳能电池；小分子电子给体材料; 中心共轭单元; 分子设计; 结晶性

\title{
Research Progress of Small Molecule Donors with High Crystallinity in All Small Molecule Organic Solar Cells

\author{
Min Lv ${ }^{a, b}$ Ruimin Zhou ${ }^{a, b} \quad \mathrm{Kun} \mathrm{Lu}^{*, a, b} \quad$ Zhixiang Wei ${ }^{a, b}$ \\ $\left({ }^{a}\right.$ CAS Key Laboratory of Nanosystem and Hierarchical Fabrication, CAS Center for Excellence in Nanoscience, \\ National Center for Nanoscience and Technology, Beijing 100190, China)
} \\ $\left({ }^{b}\right.$ University of Chinese Academy of Sciences, Beijing 100049, China)
}

\begin{abstract}
In the past few decades, organic solar cells (OSCs) have been extensively studied due to their advantages of semitransparency, light-weight and flexibility, which are considered to be an important renewable energy source in the future. Recently, bulk heterojunction all-small molecule organic solar cells (BHJ ASM-OSCs) composed of p-type small molecule donors and n-type non-fullerene acceptors as the active layers have achieved remarkable development and the power conversion efficiencies (PCEs) have exceeded 15\%. The advantages of non-fullerene acceptors over fullerene competitors are their easily tunable energy levels, better absorption properties and proper molecular designs, which allow ASM-OSCs to achieve significantly higher open-circuit voltages, higher photocurrents and superior stability, thus extending the device lifetime of OSCs. Compared with p-type polymer donors, p-type small molecule donors have unique advantages, such as well-defined molecular structures, easy purification and low batch-to-batch variations. Although ASM-OSCs are expected to take advantages of non-fullerene acceptors and small molecule donors simultaneously, in consequence of inappropriate crystallinity and nano-scale bi-continuous interpenetrating networks in blended films resulting from similar acceptor-donor-acceptor (A-D-A) structures and physicochemical properties between small molecule donors and non-fullerene acceptors, the PCEs of current state-of-the-art ASM-OSCs are still much lower than that of polymer-based OSCs. In this review, based on the expansion of the central conjugated units of small molecular donors, we summarized the crystallinity of benzodithiophene (BDT), naphthodithiophene (NDT) and dithienobenzodithiophene (DTBDT) donors from the perspective of molecular design and provided suggestions for further molecular design and morphology improvement.
\end{abstract}

Keywords all small molecule organic solar cell; small molecule donor; central conjugated unit; molecular design; crystallinity

\section{1 引言}

1995 年以来, 溶液加工的体异质结有机太阳能电 池(BHJ OSCs)开始得到广泛的学术研究和商业关注, 其 拥有重量轻、成本低、半透明、柔性和可大面积组装等
优势, 有机太阳能电池被认为将是硅为代表的无机太阳 能电池的有效补充, 成为下一代主要的可再生能源载体 之一[1].

按照体异质结有机太阳能电池活性层材料的种类

*E-mail:1vk@nanoctr.cn

Received September 27, 2020; published November 30, 2020.

Project supported by the National Natural Science Foundation of China (Nos. 21822503, 51973043, 21534003, 21721002) and Youth Innovation Promotion Association.

项目受国家自然科学基金(Nos. 21822503, 51973043, 21534003, 21721002)和青年创新促进协会基金资助. 
不同, 可分为富勒烯型有机太阳能电池和非富勒烯型有 机太阳能电池, 富勒烯型有机太阳能电池的受体材料是 富勒烯或其衍生物小分子材料(如 $\mathrm{C}_{60}, \mathrm{PC}_{61} \mathrm{BM}, \mathrm{PC}_{71} \mathrm{BM}$ 等), 给体材料是聚合物或小分子; 自 1993 年 $\mathrm{C}_{60}$ 被发现 是一种优异的受体材料以来 ${ }^{[2]}$, 得益于球型分子结构的 富勒烯及其衍生物拥有优异的电荷传输性能和与给体 材料优异的混溶性等优势, 富勒烯型有机太阳能电池的 研究在接下来的二十年间越来越广泛, 其光电转换效率 已经突破 $11 \%{ }^{[3]}$. 但是, 富勒烯型小分子有着本身无法 避免的缺点, 例如吸光性能弱, 光吸收系数低, 难以纯 化, 带隙可调性差等, 限制了富勒烯型有机太阳能电池

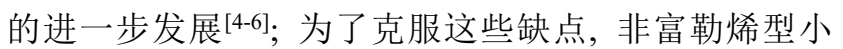
分子受体应运而生, 与富勒烯相比, 非富勒烯电子受体 具有在可见光甚至近红外(NIR)区域强的吸收、电子迁 移率高、能级可调、器件稳定性好、易于合成和纯化等 优点 ${ }^{[7-10]}$. 由于这些优点, 非富勒烯电子受体已经取得 了迅速的进展 ${ }^{[11-13]}$.

其中, 共轭聚合物给体-小分子受体有机太阳能电 池的效率已经突破 $18 \%{ }^{[14]}$, 小分子给体-非富勒烯小分 子受体的全小分子有机太阳能电池的效率已经突破 $15 \%{ }^{[15]}$. 全小分子电池的效率低于聚合物电池主要由于 小分子给体材料和小分子受体材料的化学结构和物理 化学性质高度相似, 结晶性难以调控, 很难实现合适的 相分离, 因此全小分子有机太阳能电池的短路电流 $\left(J_{\mathrm{SC}}\right)$ 和填充因子(FF)较低. 但是, 相比于共轭聚合物给体材 料, 小分子给体材料拥有明确的分子结构, 易于调节能 级和合成批次性差异小等优点 ${ }^{[16-18]}$, 使其得到了广泛的 研究; 小分子给体的结构一般分为 D-A 型、D-A-D 型和 A-D-A 型, 其中 A-D-A 型的小分子给体材料已经取得了 巨大的成功, 这种类型的小分子是由中间富电子 $\mathrm{D}$ 单元 和两端缺电子 $\mathrm{A}$ 单元以及之间的 $\pi$ 共轭连接单元组成, 分子骨架中的 D-A 连接可以实现优异的分子内电荷转 移性能, 且 A-D-A 型小分子的端基拥有比其他结构更 高密度的电子云分布, 这促进了电池体系中的激子解离 和电荷传输且使得体系拥有更小的能量损失; 另外, 由 于分子的 LUMO 和 HOMO 分别是主要由分子的端基和 中间单元决定的, 所以通过精准地调节 A-D-A 型小分 子的端基和中间单元可以使给体材料实现宽且强的吸 收、与受体相配的能级以及拥有合适相分离的分子堆积 和结晶性, 从而可以使电池实现高的光伏性能; 此外, A-D-A 型小分子给体显示更好的化学稳定性以及由于 端基基团的强连接使得分子间堆积非常紧密, 这有利于 活性层中形成稳定的相分离形貌, 从而提高电池的稳定 性, 有利于商业化应用 ${ }^{[19]}$. 因此, 开发新型的 A-D-A 型 小分子给体仍然是接下来的研究重点, 本综述中涉及的 给体材料均是 A-D-A 型小分子给体.

全小分子有机太阳能电池若能充分结合非富勒烯 受体小分子和 A-D-A 型给体小分子的优势, 便有望超 越聚合物有机太阳能电池的性能 ${ }^{[20-22]}$. 但目前的研究大
多数侧重于非富勒烯小分子受体的研究, 而小分子给体 (特别是寡聚物型的小分子给体)的研究相对滞后，性能 优异的小分子给体极为稀少，因此设计合成新型的小分 子给体尤为紧迫与重要; 此外, 优异的全小分子有机太 阳能电池需要给体与受体间形成合适的纳米级互穿网 络结构, 即合适大小的相分离尺度, 能实现电荷分离与 电荷传输之间的平衡, 这将与给体和受体小分子材料的 结晶性密切相关, 高结晶性的材料将拥有高的电荷迁移 率, 有利于空穴或电子的传输, 但同时形成的较大相区 将不利于激子扩散后的解离, 降低电荷产生的效率; 所 以，明确影响材料结晶性的因素，得到调控给受体结晶 性的措施, 进而获得优异相分离形貌的活性层也是接下 来的研究重点.

以给体小分子为例, 影响和调控给体材料结晶性的 方面有：(1)小分子本身的结构，例如分子的平面性、长 径比和对称性等, 由此使得小分子拥有不同的偶极矩和 极性，以及分子间的一些弱相互作用，例如氢键、范徳 华力、 $\pi-\pi$ 相互作用和卤键作用等，均会对材料内分子 之间的堆积和结晶性产生影响; 以往研究发现, 在分子 设计中引入 “ $\mathrm{O}-\mathrm{S}$ ”、“ $\mathrm{B}-\mathrm{N}$ ” 或 “S-F” 等非共价构象锁 策略以及空间位阻更小的基团，例如呋喃取代噻吩和使 用更小体积的取代基，也可采用不对称侧链取代或不对 称端基取代以及选择电子云密度较高的端基基团等均 可实现分子结晶性的调控 ${ }^{[23-26]}$. (2)给体小分子和受体小 分子的比例、添加剂和溶剂的选择使给受体分子在成膜 过程中产生相互作用和调节，也会显著影响彼此在混合 膜中的结晶性, 如对二元体系, 通过尝试不同的给受体 匹配、不同的 $\mathrm{D} / \mathrm{A}$ 比和不同浓度的前驱体溶液，以及选 择更合适的加工溶剂和添加剂, 尤其对于一些对后处理 工艺不敏感的材料, 可使混合膜中给受体在成膜过程中 实现更好的混溶性和结晶性等; 对于三元体系，“合金” 策略是一种获得优异结晶性混合膜的有效措施，例如: 在第三组分中，引入与第一受体组分拥有相似结构的高 结晶性受体材料以及与第一给体材料拥有相似结构但 结晶性较低的给体材料，使得二者形成 “合金” 状态，这 样的三元体系有望拥有比其二元体系更连续的能级、更 强且宽的吸收和更合适的结晶性 ${ }^{[27-31]}$. (3)此外, 对混合 膜进行后处理加工, 例如热退火、溶剂退火和后溶剂处 理等, 也可实现对材料内的分子进行重新排列和调整, 进而调控材料的结晶性; 例如: 对成膜后的混合膜采用 不同温度的热退火、不同溶剂和处理时间的溶剂退火以 及在对薄膜进行后溶剂涂覆, 如极性较大的甲醇和丙酮 等, 均是调控材料结晶性的有效措施 ${ }^{[32-34]}$. 由此, 通过 合理的分子设计以及器件加工工艺, 可实现对材料结晶 性的精准调控, 使混合膜中实现适中的给受体结晶性, 进一步获得优异纳米级互穿网络形貌的活性层材料, 有 利于提升电池中载流子的分离、传输和提取性能, 降低 体系中的单分子及双分子复合和能量损失，提高对太阳 光的利用和电池器件的稳定性以及光伏性能 ${ }^{[35-41]}$. 
本综述以全小分子有机太阳能电池中的 A-D-A 型 给体小分子的中心共轭单元的扩展为主线, 从分子设计 和后处理工艺两方面汇总了以往对苯并二噻吩(BDT)、 萘并二噻吩(NDT)和二噻并苯并二噻吩(DTBDT)为核的 三类小分子材料结晶性的研究, 并为给体小分子材料进 一步的分子设计和形貌调控提出建议, 为进一步提高全 小分子有机太阳能电池的效率提供参考.

\section{2 苯并二噻吩类给体小分子的设计和材料结晶 性的调控}

苯并二噻吩 $(\mathrm{BDT})$ 单元是 $\mathrm{A}-\mathrm{D}-\mathrm{A}$ 型给体小分子材料 中一种有希望并广泛使用的给体(D)单元, 其由一个苯 环左右各并一个单噻吩组成; 作为中心共轭的富电子单 元, 有效地促进了 A-D-A 型给体小分子内的电荷传输,
且共轭稠环单元提供了较大的 $\pi$ 电子离域空间，促进了 分子间较强的 $\pi-\pi$ 相互作用，从而可以实现分子间的紧 密堆积, 有利于得到结晶性好的材料; 同时, 中心苯环 上的 4,8 位置可以很容易地用各种侧链(包括烷基、烷氧 基或芳香族)进行修饰，这使得 BDT 类材料在有机光伏 (OPV) 领域得到了广泛的开发和应用 ${ }^{[42-46]}$. 近几年来, BDT 类小分子给体与非富勒烯小分子受体的研究越来 越多, 且已经实现了很好的进展. 接下来, 我们总结了 BDT 类小分子给体与非富勒烯小分子受体的一些研究, 从侧链、端基和 $\pi$ 桥调控等方面, 分析了分子设计对 BDT 类小分子给体材料结晶性的影响, 进而分析对活 性层形貌和电池性能的影响. 文章介绍的苯并二噻吩类 小分子电子给体材料的化学结构见图 1 和图 2, 其在 ASM-OSCs 中的光伏性能参数见表 1 .

表 1 苯并二噻吩类小分子电子给体材料在 ASM-OSCs 中的光伏性能

Table 1 Photovoltaic properties of BDT-based small molecule electron donors in ASM-OSCs

\begin{tabular}{|c|c|c|c|c|c|c|c|c|c|}
\hline Donor & HOMO/LUMO (eV) & $E_{\mathrm{g}}{ }^{a} / \mathrm{eV}$ & Acceptor & $\begin{array}{c}\mu_{\mathrm{h}} \times 10^{-4} / \\
\left(\mathrm{cm}^{2} \cdot \mathrm{V}^{-1} \cdot \mathrm{s}^{-1}\right)\end{array}$ & $V_{\mathrm{oc}} / \mathrm{V}$ & $J_{\mathrm{sc}} /\left(\mathrm{mA} \cdot \mathrm{cm}^{-2}\right)$ & $F F / \%$ & $\mathrm{PCE} / \%$ & Reference \\
\hline 1 & $-5.31 /-3.03$ & 1.87 & IDIC & 0.77 & 0.977 & 15.21 & 65.46 & 9.73 & [47] \\
\hline 2 & $-5.28 /-3.01$ & 1.87 & IDIC & 0.79 & 0.955 & 10.51 & 54.89 & 5.51 & [47] \\
\hline 3 & $-5.48 /-3.56$ & 1.90 & IDIC & 3.46 & 0.98 & 14.22 & 65 & 9.06 & [49] \\
\hline 4 & $-5.50 /-3.56$ & 1.90 & IDIC & 0.00374 & 0.99 & 0.57 & 27 & 0.15 & [49] \\
\hline 5 & $-5.33 /-3.18$ & 1.82 & IDIC & 1.48 & 0.98 & 15.92 & 71.15 & 11.10 & [48] \\
\hline 6 & $-5.39 /-3.35$ & 1.86 & $\mathrm{~F}-2 \mathrm{Cl}$ & 2.10 & 0.95 & 15.72 & 62.8 & 9.37 & {$[50]$} \\
\hline 7 & $-5.40 /-3.24$ & 1.83 & $\mathrm{~F}-2 \mathrm{Cl}$ & 2.80 & 1.00 & 16.82 & 62.6 & 10.45 & {$[50]$} \\
\hline 8 & $-5.31 /-3.36$ & 1.79 & $\mathrm{~F}-2 \mathrm{Cl}$ & 1.37 & 0.88 & 14.23 & 55.6 & 6.95 & {$[50]$} \\
\hline 9 & $-5.29 /-3.32$ & 1.83 & $\mathrm{~F}-2 \mathrm{Cl}$ & 1.13 & 0.99 & 9.36 & 52.3 & 4.85 & [50] \\
\hline 10 & - & - & $\mathrm{BO}-4 \mathrm{Cl}$ & 23 & 0.83 & 25.27 & 73 & 15.3 & [51] \\
\hline 11 & - & - & $\mathrm{BO}-4 \mathrm{Cl}$ & 14 & 0.83 & 18.60 & 72 & 11.2 & [51] \\
\hline 12 & $-5.24 /-3.41$ & 1.57 & IDIC & 0.872 & 0.90 & 13.98 & 65.20 & 8.23 & {$[52]$} \\
\hline 13 & $-5.19 /-3.37$ & 1.57 & IDIC & 0.726 & 0.90 & 12.05 & 57.20 & 6.21 & {$[52]$} \\
\hline 14 & $-5.37 /-2.81$ & 1.88 & Y6 & 3.87 & 0.866 & 23.25 & 69.9 & 14.07 & [53] \\
\hline 15 & $-5.32 /-2.81$ & 1.85 & Y6 & 3.67 & 0.825 & 23.23 & 67.7 & 12.94 & [53] \\
\hline 16 & $-5.25 /-2.78$ & 1.85 & Y6 & 4.12 & 0.805 & 23.59 & 67.0 & 12.72 & [53] \\
\hline 17 & $-5.39 /-3.38$ & 2.19 & Y6 & 5.18 & 0.854 & 21.55 & 72.35 & 13.34 & [54] \\
\hline 18 & $-5.37 /-3.37$ & 2.19 & Y6 & 4.17 & 0.870 & 21.21 & 61.35 & 11.33 & [54] \\
\hline 19 & $-5.43 /-3.39$ & 1.93 & IDIC-4F & 1.18 & 0.939 & 17.30 & 63.2 & 10.30 & {$[55]$} \\
\hline 20 & $-5.46 /-3.47$ & 1.94 & IDIC-4F & 4.61 & 0.943 & 18.30 & 70.2 & 12.10 & [55] \\
\hline 21 & $-5.64 /-3.61$ & 1.99 & $\mathrm{~F}-2 \mathrm{Cl}$ & 0.856 & 1.07 & 13.46 & 53.20 & 7.66 & [56] \\
\hline 22 & $-5.34 /-3.53$ & 1.78 & Y6 & 3.01 & 0.85 & 22.25 & 56.4 & 10.67 & {$[57]$} \\
\hline 23 & $-5.46 /-3.70$ & 1.78 & Y6 & 2.72 & 0.86 & 24.17 & 65.5 & 13.61 & [57] \\
\hline 24 & $-5.56 /-3.35$ & 1.90 & IDIC & 3.48 & 1.06 & 4.75 & 29.31 & 1.56 & [59] \\
\hline 25 & $-5.54 /-3.31$ & 1.90 & IDIC & 46.7 & 1.04 & 10.10 & 58.84 & 6.17 & [59] \\
\hline 26 & $-5.30 /-3.41$ & 1.79 & IDIC-4F & 4.29 & 0.91 & 11.04 & 41.00 & 10.69 & {$[60]$} \\
\hline 27 & $-5.31 /-3.43$ & 1.82 & IDIC-4F & 6.94 & 0.89 & 11.46 & 45.00 & 11.15 & [60] \\
\hline 28 & $-5.38 /-3.63$ & 1.81 & IDIC & 2.49 & 0.895 & 13.00 & 65.58 & 7.62 & [61] \\
\hline 29 & $-5.39 /-3.59$ & 1.89 & IDIC & 4.26 & 0.942 & 15.38 & 71.15 & 10.29 & [61] \\
\hline 30 & $-5.59 /-3.34$ & 1.87 & IDIC-4Cl & 0.417 & 0.564 & 4.90 & 33.90 & 0.90 & [62] \\
\hline 31 & $-5.58 /-3.39$ & 1.82 & IDIC-4Cl & 3.83 & 0.865 & 20.10 & 71.30 & 12.40 & [62] \\
\hline 32 & $-5.55 /-3.37$ & 1.84 & IDIC-4Cl & 1.58 & 0.870 & 14.20 & 67.0 & 8.25 & {$[62]$} \\
\hline 33 & $-5.51 /-3.34$ & - & IT-4F & 0.327 & 0.893 & 16.66 & 64.00 & 9.52 & [63] \\
\hline 34 & $-5.50 /-3.32$ & - & IT-4F & 1.74 & 0.909 & 18.27 & 68.00 & 11.24 & [63] \\
\hline 35 & $-5.50 /-3.32$ & - & IT-4F & 0.555 & 0.929 & 17.92 & 63.00 & 10.52 & [63] \\
\hline 36 & $-5.52 /-3.33$ & - & IT-4F & 0.314 & 0.928 & 16.15 & 61.00 & 9.14 & {$[63]$} \\
\hline 37 & $-5.05 /-3.30$ & 1.75 & IDIC & 6.45 & 0.88 & 15.37 & 66.56 & 9.01 & [64] \\
\hline 38 & $-5.05 /-3.30$ & 1.75 & IDIC & 5.44 & 0.87 & 14.85 & 64.88 & 8.36 & [64] \\
\hline 39 & $-5.40 /-3.61$ & 1.79 & IDIC & 2.40 & 1.01 & 14.60 & 53.00 & 7.80 & {$[66]$} \\
\hline 40 & $-5.25 /-3.55$ & 1.77 & IDIC & 3.50 & 0.97 & 15.15 & 62.50 & 9.20 & [66] \\
\hline
\end{tabular}




\begin{tabular}{|c|c|c|c|c|c|c|c|c|c|}
\hline Donor & HOMO/LUMO (eV) & $E_{\mathrm{g}}{ }^{a} / \mathrm{eV}$ & Acceptor & $\begin{array}{c}\mu_{\mathrm{h}} \times 10^{-4} / \\
\left(\mathrm{cm}^{2} \cdot \mathrm{V}^{-1} \cdot \mathrm{s}^{-1}\right)\end{array}$ & $V_{\mathrm{oc}} / \mathrm{V}$ & $J_{\mathrm{sc}} /\left(\mathrm{mA} \cdot \mathrm{cm}^{-2}\right)$ & $F F / \%$ & $\mathrm{PCE} / \%$ & Reference \\
\hline 41 & $-5.40 /-3.27$ & 1.79 & Y6 & 16.9 & 0.84 & 21.1 & 68.40 & 12.30 & {$[67]$} \\
\hline 42 & $-5.36 /-3.24$ & 1.76 & Y6 & 16.8 & 0.83 & 22.3 & 56.20 & 10.8 & {$[67]$} \\
\hline 43 & $-5.39 /-3.38$ & - & Y6 & 3.30 & 0.854 & 21.55 & 72.35 & 13.34 & {$[68]$} \\
\hline 44 & $-5.40 /-3.40$ & - & Y6 & 3.93 & 0.853 & 22.38 & 72.27 & 13.80 & [68] \\
\hline 44 & $-5.40 /-3.40$ & - & N3 & - & 0.840 & 23.81 & 70.22 & 14.09 & {$[68]$} \\
\hline 45 & $-5.02 /-3.27$ & 1.72 & O-IDTBR & 2.21 & 1.15 & 11.06 & 50.00 & 6.36 & {$[108]$} \\
\hline 23 & $-5.42 /-3.70$ & - & Y6 & 9.78 & 0.838 & 23.75 & 77.11 & 15.34 & {$[15]$} \\
\hline
\end{tabular}

${ }^{a}$ 由给体材料吸收光谱的最大吸收边计算得到: $E_{\mathrm{g}}=1240 / \lambda_{\text {max }}(\mathrm{nm})$.

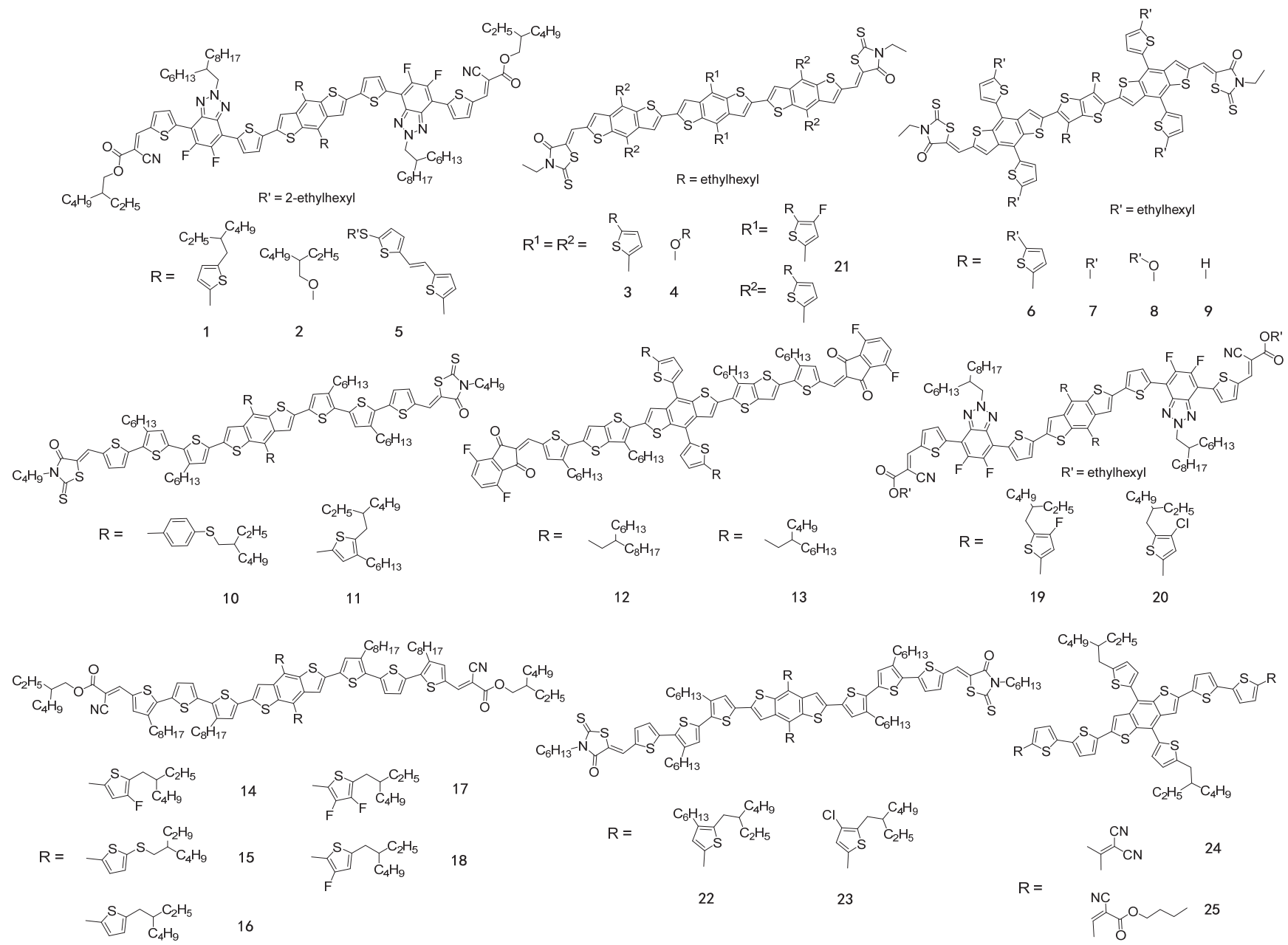

图 1 苯并二噻吩类小分子电子给体材料的化学结构 $(1 \sim 25)$

Figure 1 Chemical structures of BDT-based small molecule electron donors $(\mathbf{1} \sim \mathbf{2 5})$

\section{1 侧链调控}

以往的研究表明, 通过对 A-D-A 型给体小分子的 侧链进行合理地调控可以改善形貌和获得好的光伏性 能.

其中, 分子侧链的共轭取代是一种有效的策略. 李 永舫课题组 ${ }^{[47]}$ 设计并合成了一种新的溶液可加工的 A-D-A 型有机小分子 $\mathbf{1}$ (图 1), 其以双噻吩-苯并二噻吩 $(\mathrm{BDTT})$ 为中心给体单元, 氟苯并三唑(FBTA)为受体单 元, 在分子末端引入了氰基乙基己基乙酸酯单元进一步 拓展分子的共轭平面; 同时, 为了研究噻吩共轭侧链对 $\mathrm{p}$ 型有机半导体材料结晶性的影响, 在 BDT 单元上连接 烷氧基侧链的小分子 2 (图 1)也被合成出来. 如图 3A, 3B

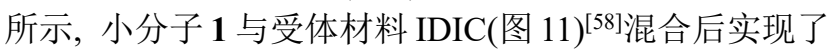
edge-on 和 face-on 共同存在的结晶取向, 且在热处理后 结晶性明显增强, 这使得在混合膜中形成了三维的电荷 传输通道, 然而小分子 2 与 IDIC 混合后主要是 edge-on 结晶取向, 三维的电荷传输通道很少; 作者进一步研究 证明，相比于小分子 2 , 拥有噻吩共轭侧链的小分子 1 与 IDIC 拥有更高的相互作用参数, 即更好的混溶性, 使 得混合膜拥有更强且有序的双模型结晶取向，从而小分 子 1 为给体材料的电池拥有更好的光伏性能, PCE 最高 

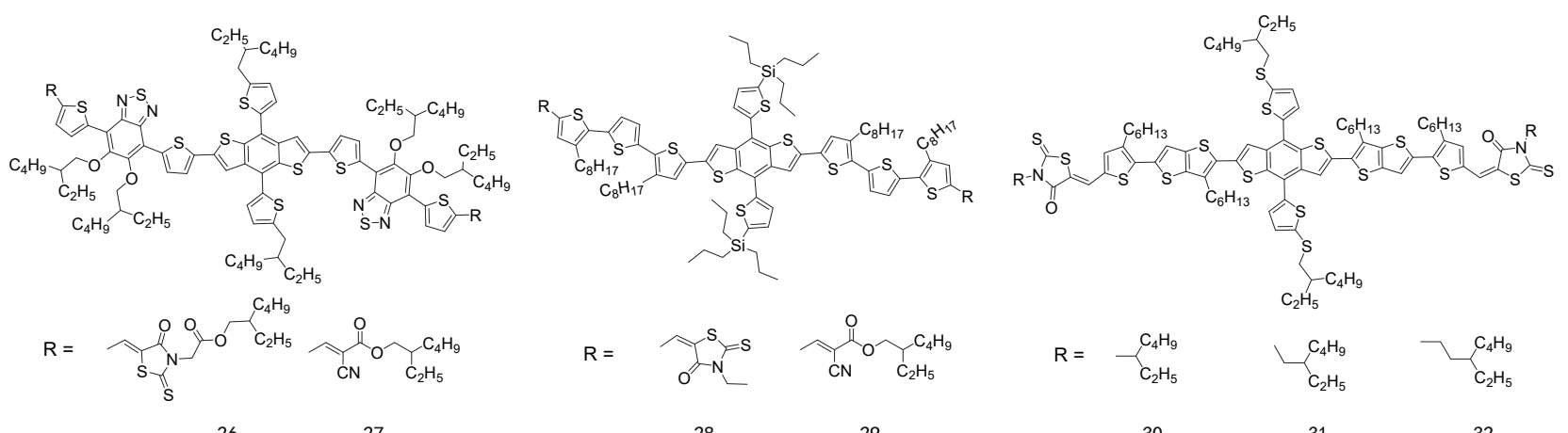

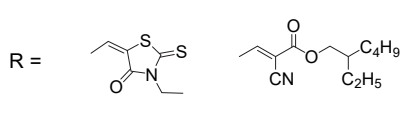

29

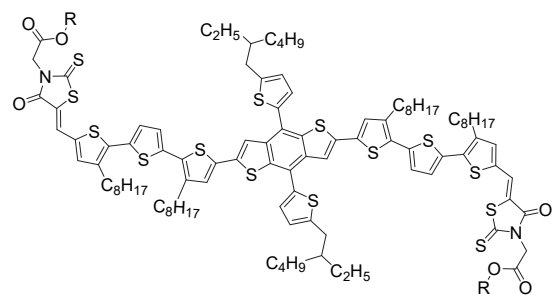

$$
\begin{array}{ll}
\mathrm{R}=\text { 2-ethylhexyl } & 37 \\
\mathrm{R}=n \text {-octyl } & 38
\end{array}
$$

36

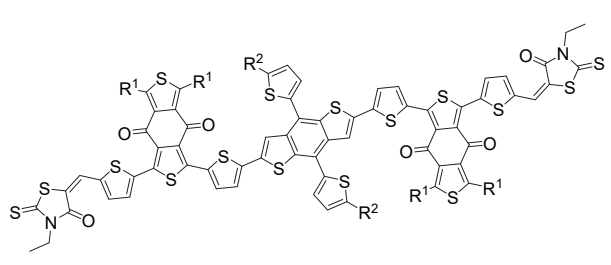

$\mathrm{R}^{1}=$ 2-butyloctyl

$\mathrm{R}^{2}=$ 2-ethy|hexyl

39

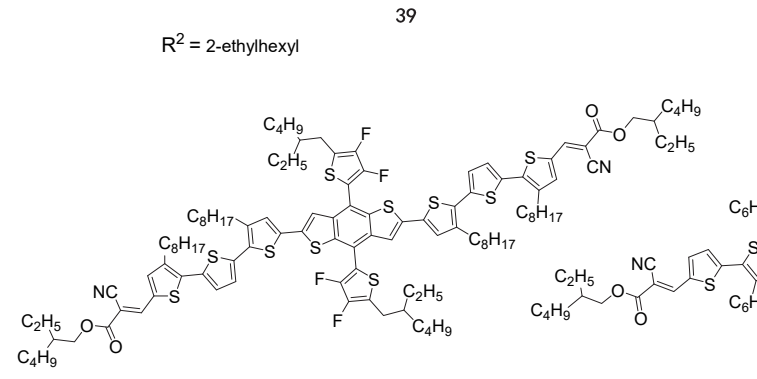

43

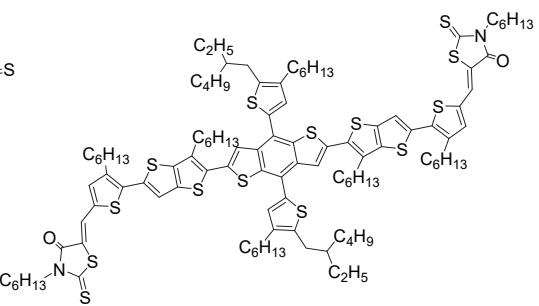

41

44

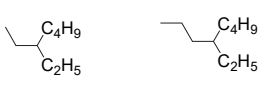

31

32

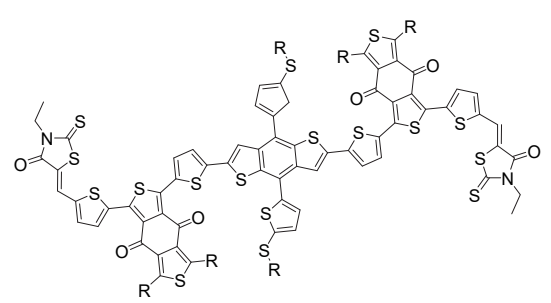

$\mathrm{R}=-_{\mathrm{C}_{2} \mathrm{H}_{5}}^{\mathrm{C}_{4} \mathrm{H}_{9}}$

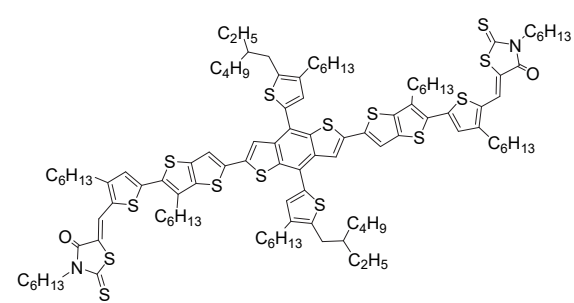

42

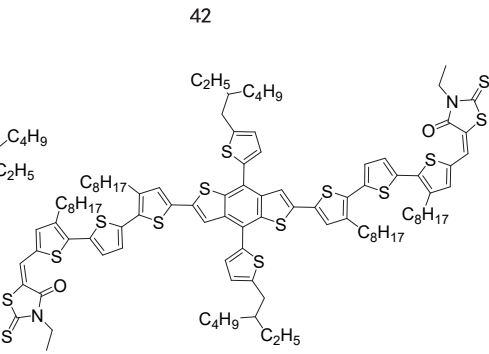

45

图 2 苯并二噻吩类小分子电子给体材料的化学结构 $(26 \sim 45)$

Figure 2 Chemical structures of BDT-based small molecule electron donors $(\mathbf{2 6} \sim \mathbf{4 5})$

达到了 $9.73 \%$.

随后, 为了研究更大平面的共轭侧链取代对给体材 料结晶性的影响, 李永舫课题组 ${ }^{[48]}$ 设计并合成了侧链 为烷硫基-亚噻吩乙烯噻吩(TVT-SR)的小分子 5 (图 1); 相比于小分子 1, TVT-SR 共轭侧链的延长拓宽了小分子 5 中 $\pi$ 电子的离域空间, 使其拥有更强的分子间相互作 用, 材料的自组装性和结晶性更强, 与 IDIC 混合后的薄 膜在热处理之后显示更好的双连续互穿网络和更高且 平衡的空穴迁移率, PCE 提升到了 $11.1 \%$, 且 BDT(TVT-SR $)_{2}$ 体系拥有更好的热稳定性和光稳定性. 这项研究工作证实了拓宽分子的共轭平面将会有效调
控给体材料的结晶性，促进形成更优异的混合膜形貌和 电池性能.

类似地, 为了研究烷基噻吩侧链与烷氧基侧链对材 料结晶性的不同影响, 侯剑辉课题组 ${ }^{[49]}$ 报道了小分子 $\mathbf{3}$ 和 4(图 1), 分别由烷基噻吩和烷氧基取代的三联 BDT 为给体单元，罗丹宁为受体单元. 相比于小分子 $\mathbf{3}$, 小 分子 4 在薄膜状态下具有更强的结晶性，但是这使得其 与 IDIC 混合后形成过大的相区，相分离尺度过大，限制 了激子的解离过程, $\mathrm{PCE}$ 只有 $0.15 \%$; 而小分子 3 与 IDIC 可以形成合适的纳米级相分离形貌, 从而实现了 更好的光伏性能, PCE 为 $9.06 \%$. 作者推断造成这种差 
A

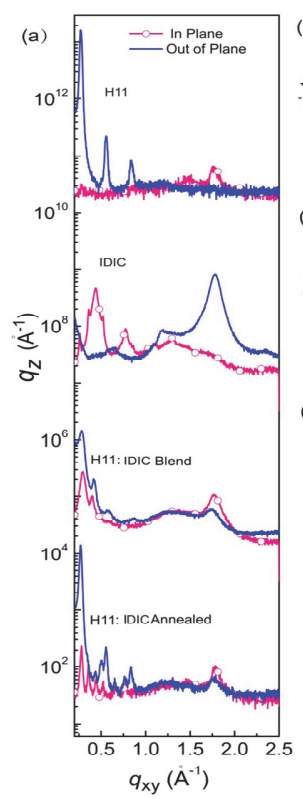

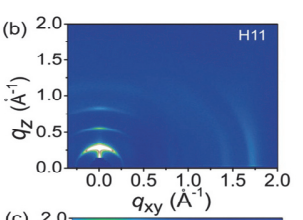

(c) 2
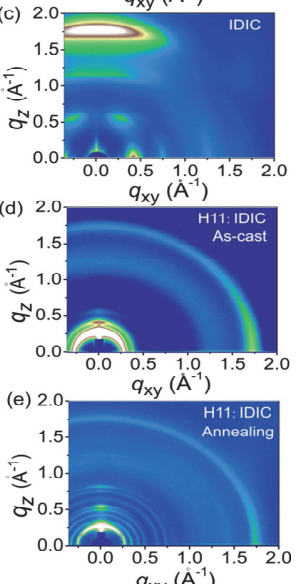

B

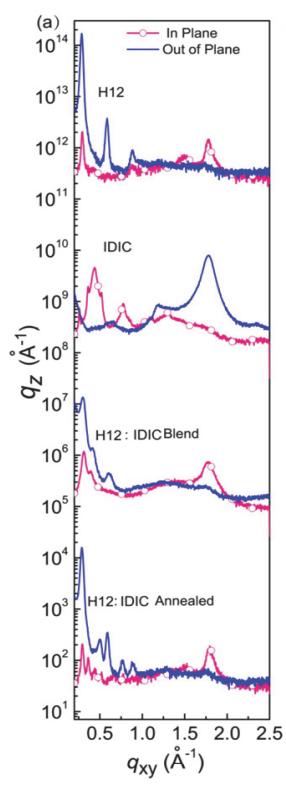

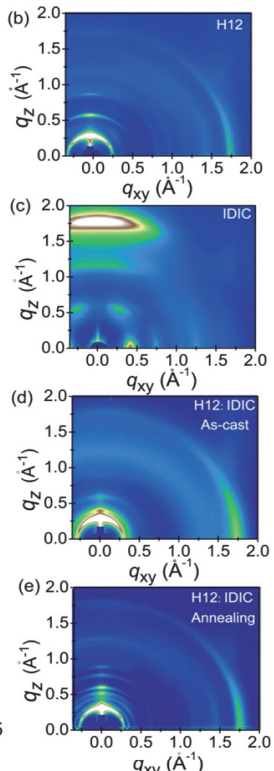

$q_{x y}\left(\AA^{-1}\right)$

图 3 A: (a) GIWAXS 切线图; GIWAXS 图像 (b) 1 (H11), (c) IDIC, (d) 1 (H11):IDIC (无后处理)和(e) 1 (H11):IDIC (热退火); B: (a) GIWAXS 切线图; GIWAXS 图像 (b) 2 (H12), (c) IDIC, (d) 2 (H12):IDIC (无后处理)和(e) 2 (H12):IDIC (热退火). 版权 2017, 美国化学学会 ${ }^{[47]}$.

Figure 3 A: (a) Line cuts of the GIWAXS images; the GIWAXS images of (b) 1 (H11), (c) IDIC, (d) 1 (H11):IDIC (as-cast) and (e) 1 (H11):IDIC (thermal annealed); B: (a) Line cuts of the GIWAXS images; the GIWAXS images of (b) 2 (H12), (c) IDIC, (d) 2 (H12):IDIC (as-cast) and (e) 2 (H12):IDIC (thermal annealed). Copyright 2017, American Chemical Society ${ }^{[47}$.

异的原因是, 烷氧基是一种极性很强的官能团, 倾向于 与 IDIC 中的端基形成强烈的相互作用, 因此混合后材 料中形成大颗粒, 影响了光伏性能.

陈永胜和耿延候课题组 ${ }^{[50]}$ 比较系统地研究了不同 共轭平面的侧链取代对给体材料结晶性的影响, 其设计 并合成了一系列宽带隙的给体小分子 $6 \sim 9$ (图 1), 具有 相同的给体中心单元和 3-乙基罗丹宁受体单元, 中心噻 吩并噻吩(TT)单元的 $\beta$ 位上分别取代 5-(2-乙基已基)噻 吩-2-基、2-乙基己基、2-乙基已基氧基和 $\mathrm{H}$ 原子; 取代 基大小的不同使分子在单键联接子单元处有不同的扭 转角, 小分子 6 和 7 的共轭主链发生较大的 “扭转”, 自 组织和聚集性较低, 小分子 8 和 9 呈现较好的平面性, 在后处理之前便自发聚集, 易在混合膜中形成过大的相 区和结晶性; 研究显示, 溶剂处理对小分子 $\mathbf{8}$ 和 9 与受 体小分子 $\mathrm{F}-2 \mathrm{Cl}$ (图 11)的混合膜影响较小, 且均存在大 部分的 edge-on 结晶取向, 影响了电荷的有效传输, 降 低了电池的光伏性能; 不同的是, 溶剂处理使小分子 $\mathbf{6}$ 和 7 与受体小分子 $\mathrm{F}-2 \mathrm{Cl}$ 混合膜的结晶性明显提升, 并 且均以 face-on 结晶取向为主导, 形成了更有序且尺度 合适的纳米结构相分离, 实现了激子分离与电荷传输之 间的平衡, PCE 分别达到了 $9.37 \%$ 和 10.45\%. 由此可见, 通过不同的侧链取代, 使分子的共轭主链发生适当的 “扭转”, 可以使共轭分子在薄膜中具有适当的聚集行 为、结晶性和微观结构, 为高性能的 NF-ASM OSCs 提 供了一种有效的分子设计策略.

近期, 为了研究苯基侧链与噻吩侧链对给体材料结 晶性的不同影响, 侯剑辉课题组 ${ }^{[51]}$ 开发出了一个以对 称苯基取代 BDT 核的小分子 10 (图 1), 突破了以往被广
泛研究的噻吩基取代, 以三并噻吩为 $\pi$ 桥, 罗丹宁为受 体单元; 相比于易扭转的噻吩基侧链小分子 11 (图 1), 苯基取代的分子构象更加稳定，于是小分子 $\mathbf{1 0}$ 的结晶 性和电学性能得到了极大地提高; 且与小分子受体 $\mathrm{BO}-4 \mathrm{Cl}$ 混合后，小分子 $\mathbf{1 0}$ 与 $\mathrm{BO}-4 \mathrm{Cl}$ (图 11)之间实现了 更强的相互作用，小分子 $\mathbf{1 0}$ 被 BO-4Cl 诱导成与其一致 的结晶取向, 并协同优化混合膜形成了小尺寸聚集的纤 维状形貌, 从而实现了高达 $15.3 \%$ 的 PCE. 这表明对称 共轭苯基取代是调控材料结晶性和制备高性能 OSC 的 一种有效的方法.

分子侧链上取代不同长度的烷基链对材料的结晶 性也会产生显著影响. 魏志祥课题组 ${ }^{[52]}$ 合成了两个侧 链长度不同的给体小分子, 长侧链小分子 12(图 1)和短 侧链小分子 13(图 1), 以 $\mathrm{BDT}$ 为核, 2-(噻吩-2-基)噻吩并 噻吩 (T-TT) 为 $\pi$ 桥, 双氟狮二酮为受体单元. 两个给体 小分子与 IDIC 混合后的光伏性能出现很大差异, 短侧 链给体参与的混合膜由于 D-A 之间弱的相互作用和早 期的结晶行为, 混合膜仍保留给受体原来的结晶取向和 结晶性, 电池的性能较差, PCE 为 $6.21 \%$; 但长侧链给体 与受体之间可以产生强的 D-A 相互作用, 在结晶之前就 可以调控受体使其拥有一致的结晶取向, 给体材料的结 晶性相比单独膜明显下降, 形成了更光滑且连续的混合 膜形貌, PCE 达到了 $8.23 \%$. 因此, 具有足够长的烷基侧 链有助于增加 BHJ 界面上给体和受体分子之间的相互 作用, 并影响活性层的结晶分子取向和结晶性, 从而获 得好的光伏性能.

除此之外, 功能原子的引入也可以有效地调控分子 的结晶性, 进而优化混合膜形貌和实现好的光伏性能. 
为了研究 $\mathrm{F}$ 化和 $\mathrm{S}$ 化对给体材料结晶性的影响, 李永舫 课题组 ${ }^{[53]}$ 合成了一系列宽带隙的给体小分子, 在它们 的噻吩共轭侧链上连接不同的取代基, 分别是连接 $\mathrm{F}$ 原 子和烷基链的小分子 14 , 引入 $\mathrm{S}$ 原子的小分子 15 和只 连接烷基链的小分子 16 (图 1). F 原子的引入使得小分子 14 间的偶极矩最大, 材料的聚集性和结晶性比其它两 个分子强, 在与 Y6(图 11)受体小分子混合并热处理后, 混合膜形成了纳米级的纤维网状结构, 会实现更好的激 子解离和电荷传输之间的平衡, 从而实现最好的光伏性 能, PCE 最高为 $14.07 \%$.

葛子义课题组 ${ }^{[54]}$ 研究了 $\mathrm{F}$ 原子数目不同的侧链对 材料结晶性的影响. 基于烷基链取代的小分子 16, 合成 了单 $\mathrm{F}$ 取代的小分子 18 和双 $\mathrm{F}$ 取代的小分子 $\mathbf{1 7}$ (图 1), 它们均具有良好的光伏性能并且 PCE 逐渐提升. 相比 小分子 18 和 16, 小分子 17 拥有更好的平面性, 使其分 子间的堆积更加紧密, 实现了更有序的主结晶取向, 有 利于空穴的传输; 同时, 小分子 17 具有较低的结晶取 向, 从而有利于改善相分离形态, 得到最高的 $\mathrm{FF}$ 为 $69.9 \%$ 和 PCE 为 $14.07 \%$.

为了研究 $\mathrm{F}$ 化和 $\mathrm{Cl}$ 化对给体材料结晶性的影响, 李 永舫课题组 ${ }^{[55]}$ 在小分子 1 的基础上设计并合成在侧链 引入 $\mathrm{F}$ 原子的小分子 $\mathbf{1 9}$ 和 $\mathrm{Cl}$ 原子的小分子 $\mathbf{2 0}$ (图 1), 卤 化的两个小分子拥有更高的结晶性; 当与受体小分子 IDID-4F(图 11)混合后, 小分子 19 的聚集和分子堆积在 动力学和热力学上受到限制, 即低的混溶性, 热退火不 能有效改善混合膜的形貌，其光伏性能与小分子 $\mathbf{1}$ 相似; 而小分子 20 拥有最高的结晶度且亚晶体的 $\pi-\pi$ 扭曲最 小, 在较小的尺度上可以实现适当聚集相区的相分离和 最高的 PCE 达到了 $12.0 \%$.

为了研究 $\mathrm{F}$ 化对给体材料结晶性的影响, 陈永胜课 题组 ${ }^{[56]}$ 在之前已报道的小分子 $\mathbf{3}$ 的基础上, 在三联 BDT 中心单元的噻吩取代基上引入 $\mathrm{F}$ 原子合成了一个新型的 小分子 21; 相比于小分子 3 , 小分子 21 材料过高的结晶 性和过量聚集, 使与受体小分子 $\mathrm{F}-2 \mathrm{Cl}$ 形成的混合膜粗 粘度过大, 具有过大尺寸的相分离, 虽然热退火后给体 相的结晶度有些下降, 混合膜的相分离变好, 但仍然没 有如小分子 3 为基础的混合膜一样, 没有形成纤维状纳 米级互穿网络形貌, 从而影响了电荷传输与激子分离, 导致了过低的 $J_{\mathrm{sc}}$ 和 FF, PCE 最高只有 $7.66 \%$. 由此可见, 在分子侧链中引入 $\mathrm{F}$ 原子对材料的结晶性和混合膜形貌 会产生显著影响.

为了研究 $\mathrm{Cl}$ 化对给体材料结晶性的影响陆仕荣课 题组 ${ }^{[57]}$ 在之前已报道的液晶小分子 22(图 1)基础上，通 过在中心 $\mathrm{BDT}$ 单元的侧链上引入负电性 $\mathrm{Cl}$ 原子, 设计 并合成了一种新型的具有更有序液晶性质的小分子 23(图 1), 液晶态的小分子即处于固态与液态的中间态, 是一种有序排列的流体; 相比于小分子 22 , 小分子 23 中 $\mathrm{Cl}$ 原子的引入降低了中心 $\mathrm{BDT}$ 单元与侧链噻吩基团
之间的二面角，增强了分子骨架的平面性和分子间的连 接，使其具有更有序的液晶性质和更高的结晶性；当与 受体小分子 Y6 混合后, 相比于小分子 $22 / Y 6$, 小分子 23/Y6 形成的混合膜表面更粗糙和更明显的纹理结构, 得到了更明显的相分离和最佳的薄膜形貌, 且在混合膜 中小分子 23 呈现 edge-on 结晶取向, Y6 呈现 face-on 结 晶取向, 由此混合膜具有平行和垂直通道共存的三维电 荷传输通道, 实现了更平衡的激子分离和电荷传输, PCE 最高达到了 $13.6 \%$. 这项工作说明, 通过引入 $\mathrm{Cl}$ 原 子可以对分子间相互作用和材料的结晶性进行精细调 节以及使用具有液晶性质的分子, 是克服相分离问题的 分子设计思路之一.

因此, 通过对给体小分子进行合理的侧链调控, 例 如引入共轭侧链、改变烷基链的长度、引入功能原子和 改变功能原子的数目等, 可以实现对给体材料结晶性的 调控, 进而获得更好相分离形貌的混合膜和光伏性能.

\section{2 端基调控}

研究显示，通过用不同的受体端基对给体小分子进 行修饰, 小分子富勒烯太阳能电池的器件性能得到了极 大的改善，这是由于改善了材料的结晶性、调节混合膜 形貌以及调整了分子能级等. 接下来, 我们列举几个典 型的 $\mathrm{BDT}$ 类小分子端基调控的实例, 包括使用不同种 类的端基、对同一种端基进行不同的修饰和双受体策略 等三个方面.

为了研究不同种类的端基对给体材料结晶性的影 响，雷爱文课题组 ${ }^{[59]}$ 设计并合成了两种具有不同受体 单元的给体小分子, 分别是端基为双氰基乙烯基的小分 子 24 和正丁基氰酯基的小分子 $\mathbf{2 5}$ (图 1), 正丁基氧酯基 的引入使小分子 25 在溶液和熔体状态下均表现出高的 结晶性, 保证其与 IDIC 混合后能形成更明显的相分离, 提高了电荷分离与传输的效率. 李哲峰和陆仕荣课题 组 ${ }^{[60]}$ 合作设计并合成了两个基于苯并噻二唑(BT)单元 且末端连接不同受体单元的小分子 26 和 27(图 2), 研究 显示，小分子 27 比 26 有更强的结晶性和分子间相互作 用, 在与受体小分子 IDIC-4F 混合并进行溶剂退火后, 由于小分子 27 的结晶性进一步提高, 混合膜表面相比 小分子 26/IDIC-4F 具有更大的粗糙度, 实现了更高且平 衡的电荷迁移率, PCE 为 $4.62 \%$, 比小分子 $26 / \mathrm{IDIC}-4 \mathrm{~F}$ 的 $4.08 \%$ 高.

类似地, 为了研究不同种类的端基对给体材料结晶 性的影响, 李永舫课题组 ${ }^{[61]}$ 设计合成了两个二维共轭 的硅烷基噻吩为中间核侧链的小分子，分别是以 3-乙基 罗丹宁为端基的小分子 28 和氰基乙酸酯为端基的小分 子 29(图 2), 小分子 28 的薄膜显示更紧密的 $\pi-\pi$ 堆积, 与 IDIC 混合后的材料表现出更多的随机结晶取向和无序 的微结构, 影响了其电池的光伏性能; 不同的是, 小分 子 29 与 IDIC 混合后均保留其原来的结晶取向, 在混合 膜中形成了合适的晶粒尺寸和三维的电荷传输通道, 极 
大地促进了电荷的分离与传输, PCE 达到了 $10.29 \%$. 因 此，不同的端基取代可以有效调控材料的结晶性和混合 膜的形貌，从而实现好的光伏性能.

另外, 对同一类的端基进行修饰也是影响小分子有 机太阳能电池材料结晶性的重要因素之一. 为了研究端 基烷基链的支点外移对给体材料结晶性的影响, 魏志祥 课题组 ${ }^{[62]}$ 报道了三种新型的小分子给体, 它们在端基 烷基链的 1, 2 和 3 位有分支点, 分别为小分子 30、31 和 32(图 2). 如图 4A, 4B 所示, 支点外移后的小分子 31 和 32 的结晶性和有序性明显变强, 三个给体小分子与 强结晶性的受体小分子 IDIC-4Cl 混合组装器件发现, 细微的分支位置偏移实现了光伏参数的巨大差异, 从小 分子 30 到 31 到 $32, J_{\mathrm{sc}}$ 由 $4.90 \mathrm{~mA} \cdot \mathrm{cm}^{-2}$ 到 $20.1 \mathrm{~mA} \cdot \mathrm{cm}^{-}$ 2 到 $14.2 \mathrm{~mA} \cdot \mathrm{cm}^{-2}$, 填充因子由 $33.9 \%$ 到 $71.3 \%$ 到 $67.0 \%$, PCE 由 $0.90 \%$ 到 $12.4 \%$ 到 $8.25 \%$, 基于小分子 31 的器件 性能优异, 主要是由于小分子 $\mathbf{3 1}$ 结晶性最高, 与受体小 分子 IDIC-4Cl 间存在适当的相互作用而形成了优异的 纳米互穿网络结构; 相比之下, 小分子 $\mathbf{3 0}$ 的结晶度和成 膜能力差, 小分子 32 参与的混合膜更为无序, 相区较 大，限制了它们的光伏性能.

类似地, 为了研究端基烷基链的长度对给体材料结 晶性的影响, 侯剑辉课题组 ${ }^{[63]}$ 合成了一系列具有相同 $\pi$ 共轭骨架三联 BDT 和端基, 但是端基罗丹宁上的烷基 链长度不同的给体小分子, 分别是 $\mathrm{C} 2$ 链的小分子 33 、 C4 链的小分子 34、C6 链的小分子 35 和 C8 链的小分子 36(图 2). 研究发现, 随着端基链的延长, 相对于祄底, 给体小分子的结晶取向发生了明显的 edge-on 到 face-on 的转变; 与受体小分子 IT-4F(图 11)混合后, 小分子 34 的器件性能最优异, 达到了最高 $11.24 \%$ 的效率, 这与混 合膜电荷迁移率的增强和 $\pi-\pi$ 堆积的相关长度密切相
关.

为了研究引入酯基的罗丹宁端基以及其上的烷基 链长度不同对给体材料结晶性的影响，陆仕荣课题 组 ${ }^{[64]}$ 首次合成了酯化的罗丹宁受体单元，作为 BDT 小 分子的端基, 并对端基上烷基链进行修饰, 合成了 2-乙 基已基取代的小分子 37 和正辛基取代的小分子 38(图 $2)$, 相比之前报道的小分子 DR3 $(\mathrm{PCE}=7.6 \%)$, 酯化罗 丹宁为端基的两个小分子材料拥有更好的结晶性和聚 集行为, 在与 IDIC 混合后均显示合适的相区和相分离, 均产生了超过 $8 \%$ 的效率. 因此，合理修饰分子的端基 基团将有效调控给体材料的结晶性，进而获得好的混合 膜形貌和光伏性能.

另外, 在 BDT 类小分子里, 双受体单元的分子被合 成研究，分子内存在两个拉电子基团，会增强分子内的 电荷传输, 是分子设计中一种可考虑的有效途径. 张茂 杰课题组 ${ }^{[65]}$ 报道了一个 $\mathrm{A}_{1}-\mathrm{A}_{2}-\mathrm{D}-\mathrm{A}_{2}-\mathrm{A}_{1}$ 型的双受体单元 小分子给体 39(图 2), 其以 BDT-T 为中心核, 单噻吩连 接的苯并二噻吩二酮(BDD)和罗丹宁为受体单元，与 IDIC 混合后的薄膜在溶剂退火之后显示更强的结晶性, 有利于电荷传输; 同时, 得益于分子较长的共轭主链, 混合膜的相纯度非常高，达到了 $100 \%$, 合适的域尺寸 促进了薄膜中激子的解离. 但是, 溶剂退火后的薄膜以 edge-on 取向为主, 这限制了器件的 FF, PCE 仅为 7.8\%. 在此之前，一个类似的双受体小分子 40 (图 2) 也被报 道 ${ }^{[66]}$ ，与小分子 39 的区别是，其中心核侧链是噻吩硫 烷基链且侧链和 BDD 单元上取代的烷基链长度更短, 得益于 $\mathrm{S}$ 原子的引入，小分子 $\mathbf{4 0}$ 有着更强的分子间相互 作用，与 IDIC 混合后有利于形成理想的薄膜形貌和有 效的激子离解, 抑制器件中的电荷复合, 从而获得优异
A

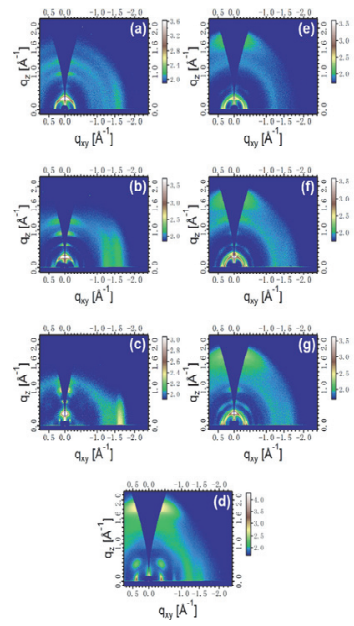

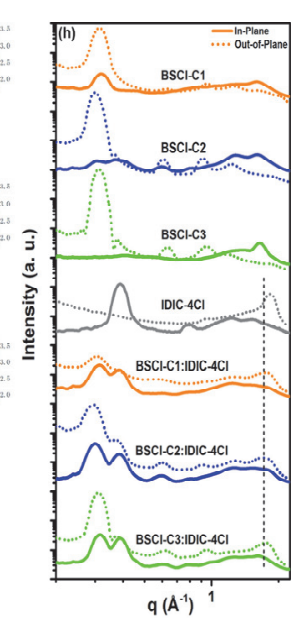

B
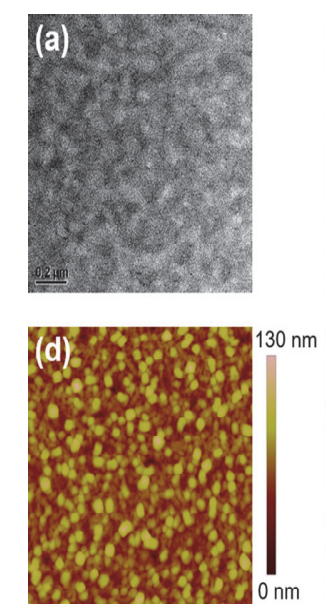
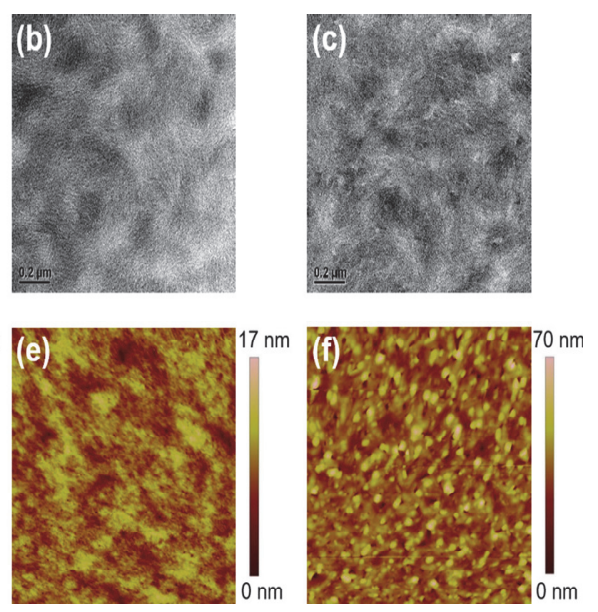

图 $4 \mathrm{~A}:(\mathrm{a} \sim \mathrm{d})$ 给体 $\mathbf{3 0}(\mathrm{BSCl}-\mathrm{C} 1), \mathbf{3 1}(\mathrm{BSCl}-\mathrm{C} 2)$ 和 $32(\mathrm{BSCl}-\mathrm{C} 3)$ 以及受体 IDIC-4Cl 单组分膜的 2D GIWAXS 图像; (e $\mathrm{g})$ 改善条件下混合膜的 2D GIWAXS 图像; (h) 改善条件下 30,31, 32 和 IDIC-4Cl 单组分及其混合膜的 1D GIWAXS 切线图; B: (a c c) 基于不同给体 30, 31 和 32 混合膜的 TEM 图像; $(\mathrm{d} \sim \mathrm{f})$ 对应的 AFM 高度图; 版权 2020, 美国化学学会 ${ }^{[62]}$.

Figure 4 A: $(\mathrm{a} \sim \mathrm{d})$ 2D GIWAXS patterns of donors 30 (BSCl-C1), 31 (BSCl-C2), and 32 (BSCl-C3) and acceptor IDIC-4Cl pure films; (e $\sim \mathrm{g}) 2 \mathrm{D}$ GIWAXS patterns of blended films under optimized conditions; (h) 1D GIWAXS curves of 30, 31, 32 and IDIC-4Cl pure and blended films under optimized conditions; B: $(\mathrm{a} \sim \mathrm{c})$ TEM images of blended films based on different donors 30, 31, and 32; $(\mathrm{d} \sim \mathrm{f})$ corresponding AFM height images. Copyright 2020, American Chemical Society ${ }^{[62]}$. 
的电流密度和填充系数, 器件的效率最高到 $9.20 \%$.

因此，对于小分子给体，使用合适的端基，对同一 种端基进行不同修饰以及使用双受体单元(双端基)等分 子设计的策略都可实现给体材料结晶性的调控, 进而影 响混合膜形貌和电池光伏性能.

\section{$2.3 \pi$ 桥调控}

在 A- $\pi-D-\pi-A$ 型有机给体小分子中, 除了侧链和端 基调控, 给体与受体之间的连接单元, 即 $\pi$ 桥, 对于分 子的结构和材料的性能也起着关键作用. 研究发现, 合 理的修饰 $\pi$ 桥将获得更优异的给体材料.

为了研究 $\pi$ 桥上烷基链的位置不同对给体材料结晶 性的影响, 陆仕荣和孙宽 ${ }^{[67]}$ 合作设计并合成了两个构 象异构的小分子给体材料, BDT 和罗丹宁分别为给体和 受体单元, 己基链取代的 T-TT 为 $\pi$ 桥, 直线骨架和稠环 的 T-TT 可以促进分子间的 $\pi-\pi$ 堆积和分子内的电荷传 输, 两个分子的不同在于, 小分子 $41 \pi$ 桥上的己基链 “向内”，小分子 $42 \pi$ 桥上的已基链 “向外” (图 2). 如 图 5A, 5B 和 5C 所示, 通过调整烷基链的位置, 小分子 41 具有比 42 更好的平面性, 从而分子间的 $\pi-\pi$ 堆积和 层堆积更加紧密, 材料的聚集性和结晶性也更好; 两个
小分子给体分别与受体 Y6 混合后发现，相比于小分子 42, 小分子 41 为给体的混合膜拥有更合适的相分离和 膜形貌，从而使得器件拥有更高的 FF，同时，这也使得 小分子 41 与 Y6 混合膜的双分子复合损失更低和载流子 寿命更高, PCE 达到了 $12.3 \%$, 高于小分子 42 为基础的 器件 $10.8 \%$.

葛子义课题组 ${ }^{[68]}$ 为了研究 $\pi$ 桥上烷基链的长度和 位置不同对给体材料结晶性的影响，其在之前报道的小 分子 43 的基础上，设计并合成出了给体小分子 44 (图 2), 小分子 $44 \pi$ 桥上的烷基链以更规则的方式排列，这有利 于烷基链的交叉，从而促进了分子的有序排列，同时缩 短的侧链也有利于更紧密的层堆积, 使得材料拥有更强 的结晶性和聚集性. 与受体小分子 Y6 混合后，在混合 膜中实现了高结晶性和合适相分离之间的平衡表现出 更高的空穴迁移率、短路电流和超过了 70\%的填充因子, PCE 达到了 13.8\%; 当与小分子受体 N3(图 11)混合后, 由于混合膜更小的粗䊁度、 $\pi-\pi$ 堆积距离和更好的双连 续互穿网络结构, PCE 进一步提升到了 $14.09 \%$.

以上研究表明, 合理的修饰分子中的 $\pi$ 桥, 将有效 调控材料的结晶性和混合膜形貌, 得到更好光伏性能的

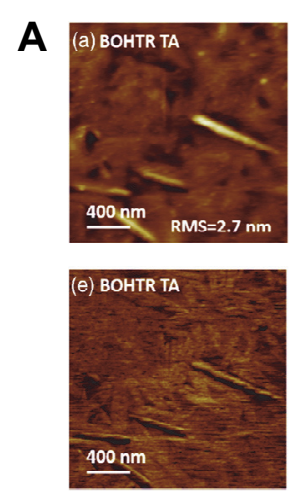

B
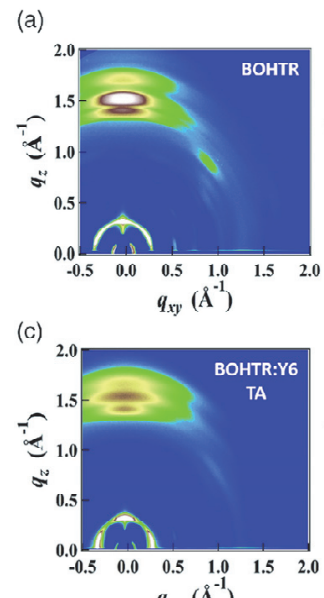

$q_{x y}\left(\AA^{-1}\right)$
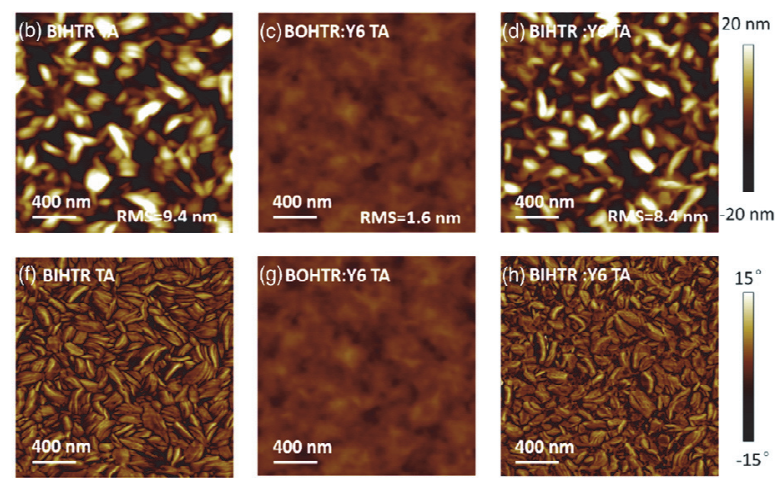

(b)

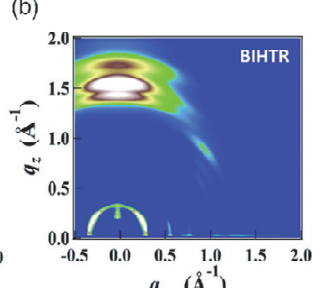

$q_{x y}\left(\AA^{-1}\right)$
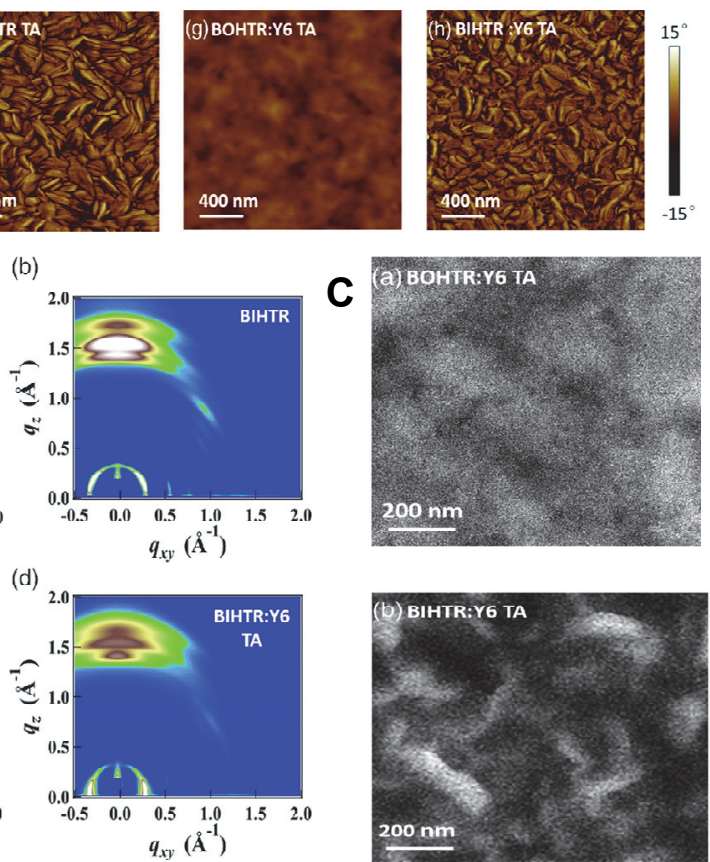

图 5 A: 单组分膜和混合膜的 AFM 高度图 (a) 单组分 42 (BOHTR) 膜, (b) 单组分 $\mathbf{4 1}$ (BIHTR) 膜, (c) 42:Y6 混合膜, (d) 41:Y6 混合膜, (e h) 它们 对应的相分离图像; B: (a, b) 单组分膜 42 和 41 在热退火后的 GIWAXS 2D 衍射图案; (c, d) 42:Y6 和 41:Y6 混合膜的 GIWAXS 2D 衍射图案; C: HAAD-STEM 图像 (a) 42:Y6, (b) 41:Y6 混合膜. 版权 2019, WILEY-VCH ${ }^{[67]}$.

Figure 5 A: AFM height images of pure and blend films (a) pure 42 (BOHTR) film, (b) pure 41 (BIHTR) film, (c) 42:Y6 blend film, and (d) 41:Y6 blend film, and $(\mathrm{e} \sim \mathrm{h})$ their corresponding phase images; B: (a, b) GIWAXS 2D diffraction patterns of 42 and 41 pure films after TA; (c, d) GIWAXS 2D diffraction patterns of 42:Y6 and 41:Y6 blends; C: HAAD-STEM images of (a) 42:Y6 and (b) 41:Y6 blend films. Copyright 2019, WILEY-VCH ${ }^{[67]}$. 
电池. 总之, 通过对 BDT 类给体小分子进行合理的侧 链、端基和 $\pi$ 桥调控等措施可以有效调节给体材料的结 晶性, 进而实现优异的混合膜形貌和电池性能. 由此可 见, 富电子性的中心共轭稠环单元可以构建高效的给体 小分子材料, 为了进一步增强分子间的相互作用, 获得 更高结晶性的材料, 理论上讲对中心共轭单元的扩展是 一个很好的思路, 由此可拓宽中心 D 单元的长度, 增大 $\pi$ 电子离域空间, 增强分子间的 $\pi-\pi$ 堆积作用, 促进得到 更高结晶性和更纯的材料. 于是, 䒺环取代苯环奋并二 噻吩(NDT)单元也被研究.

\section{3 萗并二噻吩类给体小分子的设计和材料结晶 性的调控}

不同于 BDT 单元, 芸并二噻吩(NDT)单元是由一个 萗环加两个噻吩组成的, 进一步拓宽了中心共轭单元, 理论上比 BDT 会有更强的分子间 $\pi-\pi$ 相互作用，分子间 的堆积将更加紧密, 材料结晶性会更好. 通过菜环和噻 吩不同的组合, 可以得到多种几何异构体, 在组成有机 太阳能电池的材料中, 主要有线型 NDT (1 NDT) 和 zigzag 型 NDT (z NDT)两种单元, 用做 A-D-A 型给体材 料的 D 单元; 但由于 NDT 的合成困难, 限制了其像 BDT 一样广泛的研究 ${ }^{[69-70]} .2011$ 年, Marks 课题组 ${ }^{[71]}$ 第 一次将 NDT 类给体材料 NDT(TDPP $)_{2}$ 应用于有机光伏 器件中, 与受体 $\mathrm{PC}_{61} \mathrm{BM}$ 混合组装电池效率便超过了 $4 \%$. 目前 NDT 类聚合物给体材料 ${ }^{[72-77]}$ 和小分子给体材 料已经在 OPV 领域得到开发和应用, NDT 类小分子给 体材料与富勒烯受体材料结合 ${ }^{[78-82]}$, 最高的电池效率已 经接近 $10 \%$. 接下来, 我们汇总了 NDT 类小分子给体在 全小分子电池中的研究, 分析了影响 NDT 类材料结晶 性和电池性能的原因. 文章介绍的荎并二噻吩类小分子 电子给体材料的化学结构见图 6, 其在 ASM-OSCs 中的 光伏性能参数见表 2 .

为了研究 NDT 小分子给体在富勒烯体系和非富勒 烯体系中的结晶性区别, 魏志祥课题组 ${ }^{[83]}$ 设计合成了 一种新型的 A- $\pi-D-\pi-A$ 型给体小分子 46(图 6), 以 NDT 为中心给体单元, 3-乙基罗丹宁为受体单元, 三联噻吩 为 $\pi$ 桥, 研究了小分子 $\mathbf{4 6}$ 为给体的富勒烯体系和非富勒 烯体系的光伏性能. 小分子 46 显示出很强的结晶性和 结构有序性, 与 $\mathrm{PC}_{71} \mathrm{BM}$ 和 IDIC 之间均会产生很强的相
互作用，电池的效率分别为 $7.75 \%$ 和 $6.60 \%$ ，造成差异 的原因是小分子 46 与 IDIC 形成混合膜虽然给受体相容 性更好和电荷分离效率更高, 但混合膜高的结晶性和相 分离之间的平衡不如与 $\mathrm{PC}_{71} \mathrm{BM}$ 好, 所以需要进一步调 整非富勒烯体系的混合膜形貌.

随后, 该课题组 ${ }^{[84]}$ 研究了在中心核侧链上引入 $\mathrm{S}$ 原 子对给体材料结晶性的影响, 基于小分子 46 设计合成 了小分子 47(图 6), 两者分子结构相似, 唯一的区别是 小分子 47 中心给体单元的侧链引入了 $\mathrm{S}$ 原子. 研究发 现, 由于 $S$ 引入会进一步增加分子间的 $\pi-\pi$ 堆积, 使得 小分子 47 的材料拥有更高的结晶性. 然后, 将小分子 47 与能级匹配的两个稠环受体 ITIC ${ }^{[85]}$ 和 IDIC 分别结合 组装器件, IDIC 为受体的器件效率达到了 $8.05 \%$, 而 ITIC 为受体的器件效率仅有 $1.77 \%$, 主要是由于 IDIC 受体材料比 ITIC 受体材料拥有更好的结晶性, 使得混 合膜的聚集度和粗粘度比较高, 形成了合适的相分离和 更高纯度的相区，从而实现了更有效的电荷分离和传 输; 而 ITIC 弱的结晶性使混合膜的相分离尺度过小, 不 利于电荷传输, 影响了光伏性能. 这项研究工作证明, 在 NDT 小分子侧链中引入 $\mathrm{S}$ 原子可以得到结晶性更高 的给体材料; 另外, 受体材料的结晶性对给体结晶性和 混合膜形貌有着显著影响, 结晶性好的小分子受体更适 用于 NDT 小分子给体.

接下来, 为了研究端基上不同长度的取代基对给体 材料结晶性的影响, 该课题组 ${ }^{[86]}$ 再次设计并合成了以 NDT 为中心给体单元的两个液晶给体小分子, 分别是 $\mathrm{C} 4$ 链端基小分子 48 和 C6 链端基小分子 49 (图 6), 两个 分子均具有形成液晶的能力, 液晶是一种介于晶体和液 体之间的中间态，是取向有序的流体，液晶材料具有适 中的结晶性可以更加精细地调控混合膜形貌; 如图 7A, 7B 所示, 两个液晶小分子与强结晶性的受体小分子 IDIC-4F 混合后, 均可以实现 face-on 为主导的分子堆积 取向和合适的相分离形貌，低的双分子复合和高的载流 子迁移率使填充因子均超过了 $70 \%$, 小分子 $\mathbf{4 8}$ 为基础 的器件 PCE 最高为 $9.21 \%$, 小分子 $\mathbf{4 9}$ 为基础的器件 PCE 最高为 $10.71 \%$. 类似地, 该课题组 ${ }^{[87]}$ 随后再次改变端基 上的烷基链, 合成了支链取代的给体小分子 $\mathbf{5 0}$ 和直链 取代的小分子 51(图 6), 材料的结晶性不同, 混合膜的 形貌和电池性能也不同.

表 2 菜并二噻吩类小分子电子给体材料在 ASM-OSCs 中的光伏性能

Table 2 Photovoltaic properties of NDT-based small molecule electron donors in ASM-OSCs

\begin{tabular}{cccccccccc}
\hline Donor & HOMO/LUMO $(\mathrm{eV})$ & $E_{\mathrm{g}}{ }^{a} \mathrm{eV}$ & Acceptor & $\begin{array}{c}\mu_{\mathrm{h}} \times 10^{-4} / \\
\left(\mathrm{cm}^{2} \cdot \mathrm{V}^{-1} \cdot \mathrm{s}^{-1}\right)\end{array}$ & $V_{\mathrm{oc}} / \mathrm{V}$ & $J_{\mathrm{sc}} /\left(\mathrm{mA} \cdot \mathrm{cm}^{-2}\right)$ & $F F / \%$ & PCE/\% & Reference \\
\hline $\mathbf{4 6}$ & $-5.23 /-3.50$ & 1.73 & IDIC & 0.486 & 0.89 & 13.20 & 56.60 & 6.60 & {$[83]$} \\
$\mathbf{4 7}$ & $-5.25 /-3.50$ & 1.73 & ITIC & 0.0676 & 1.00 & 5.36 & 32.85 & 1.77 & {$[84]$} \\
$\mathbf{4 7}$ & $-5.25 /-3.50$ & 1.73 & IDIC & 1.18 & 0.92 & 14.13 & 61.95 & 8.05 & {$[84]$} \\
$\mathbf{4 8}$ & $-5.25 /-3.46$ & 1.83 & IDIC-4F & 3.01 & 0.76 & 17.02 & 71.40 & 9.20 & {$[86]$} \\
$\mathbf{4 9}$ & $-5.26 /-3.46$ & 1.82 & IDIC-4F & 3.69 & 0.78 & 18.89 & 72.80 & 10.40 & {$[86]$} \\
$\mathbf{5 0}$ & $-5.27 /-3.41$ & 1.82 & IDIC-4F & 5.60 & 0.77 & 14.28 & 54.41 & 6.11 & {$[87]$} \\
$\mathbf{5 1}$ & $-5.34 /-3.46$ & 1.82 & IDIC-4F & 1.69 & 0.79 & 15.02 & 59.58 & 7.06 & {$[87]$} \\
\hline
\end{tabular}

${ }^{a}$ 由给体材料吸收光谱的最大吸收边计算得到: $E_{\mathrm{g}}=1240 / \lambda_{\text {max }}(\mathrm{nm})$. 


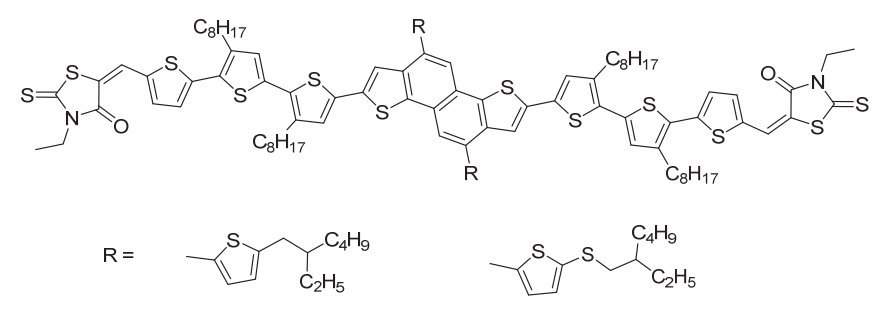

46

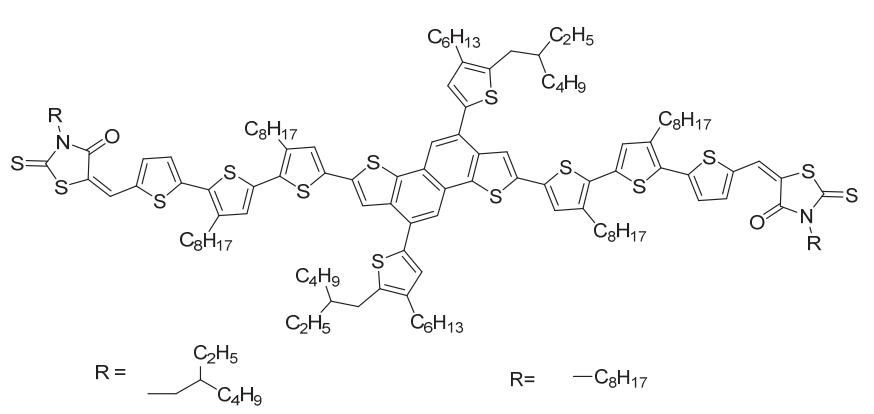

50

51

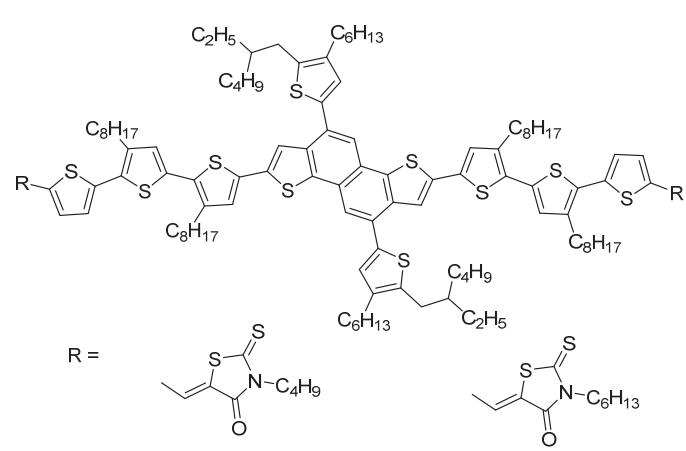

48

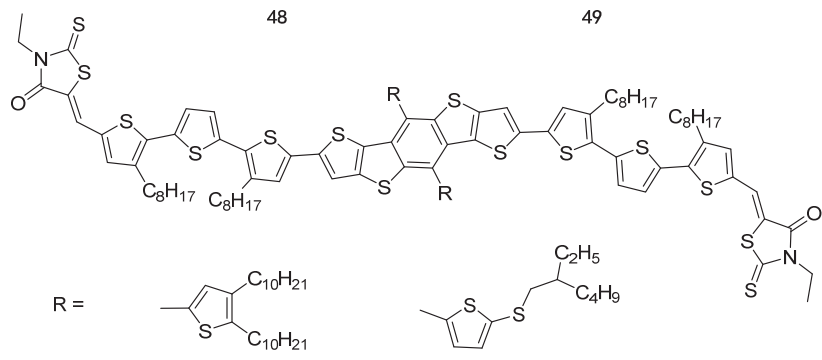

52

53

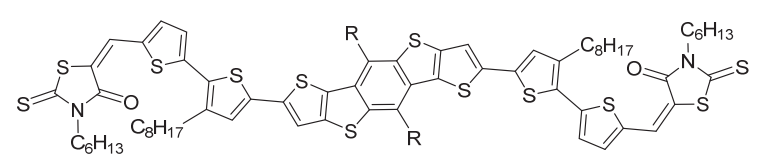

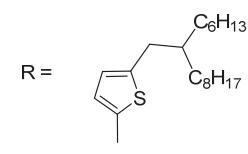

54

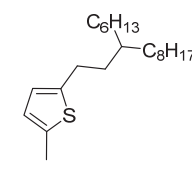

55

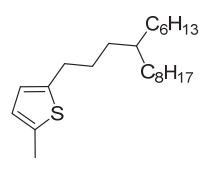

56

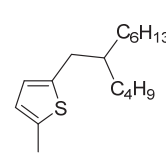

57

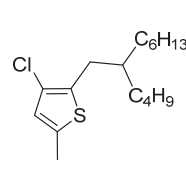

58

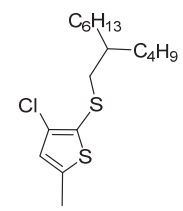

59

图 6 芸并二噻吩和二噻并苯并二并噻吩类小分子电子给体材料的化学结构

Figure 6 Chemical structures of NDT and DTBDT-based small molecule electron donors

以上工作说明, 与 $\mathrm{BDT}$ 类小分子一样, 通过侧链和 端基调控等措施可以有效调控分子的堆积取向和材料 的结晶性, 进而获得更好的混合膜形貌和光伏性能. 但 是, NDT 小分子材料的合成步骤较多, 限制了其进一步 的分子结构改造和研究, 目前 NDT 为基础的电池并没 有取得很好的光伏性能. 然而, 以 BDT 为基础的二噻并 苯二并噻吩(DTBDT)核由于其合成相对简单且中心共 轭单元相比 BDT 和 NDT 得到了进一步扩展, 预测合成 出的材料将会拥有更易调控的结晶性, DTBDT 核逐渐 得到广泛的关注和研究.

\section{4 二噻并苯并二噻吩类给体小分子的设计和材 料结晶性的调控}

二噻并苯并二噻吩 (DTBDT)单元也是现在逐渐引 起关注的 A-D-A 型给体小分子材料中 D 单元的一种. DTBDT 单元是一种线性五元稠环芳香烃的长链, 结构 上是在 $\mathrm{BDT}$ 单元的两侧各接一个噻吩, 这使得 DTBDT
比 $\mathrm{BDT}$ 和 NDT 有着更长的共轭主链和更大的 $\pi$ 电子离 域空间，进而拥有更强的分子间 $\pi-\pi$ 相互作用. 2012 年, DTBDT 为中心共轭单元的聚合物半导体材料 PDTT 首 次被用做有机太阳能电池的给体材料，便实现了 $2.24 \%$ 的效率, 从此 DTBDT 类材料在有机光伏领域得到越来 越多的研究 ${ }^{[88]}$. 从 2012 年至今, DTBDT 类材料在有机 光伏领域已经实现了很好的应用, 比如 DTBDT 类聚合 物给体材料与非富勒烯受体小分子的电池, 效率均超过 了 $10 \%{ }^{[89-90]}$; DTBDT 类小分子给体材料与富勒烯受体 材料的电池 ${ }^{[91-96]}$, 效率最高超过了 $8 \%$; 近两年, DTBDT 类小分子给体材料与非富勒烯小分子受体材料的电池, 其效率已经突破 $14 \%$, 在全小分子电池中首屈一指. 接 下来, 我们汇总了 DTBDT 类材料在全小分子电池中的 应用, 重点总结了分子设计对材料结晶性和电池性能的 影响. 文章介绍的二噻并苯并二噻吩类小分子电子给体 材料的化学结构见图 6, 其在 ASM-OSCs 中的光伏性能 参数见表 3 . 
A (a)

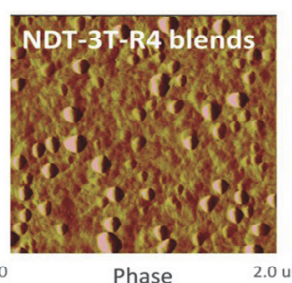

(d)

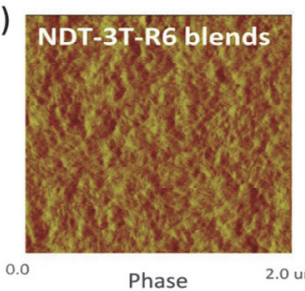

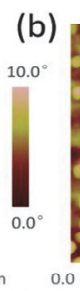

(e)
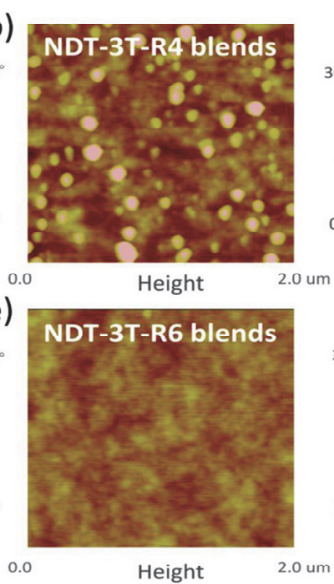

(c)

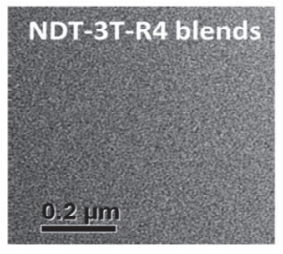

(f)

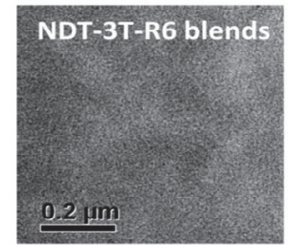

B

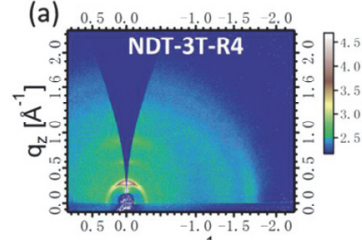

$q_{x y}\left[\AA^{-1}\right]$

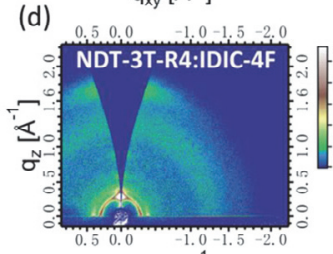

$q_{x y}\left[A^{-1}\right]$ (b) $0.50 .0 \quad 1001.5220$

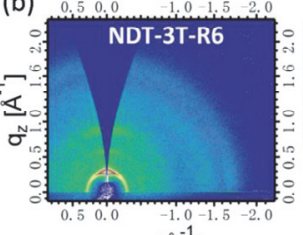

$q_{x y}\left[A^{-1}\right]$

(e) $0.50 .000 .5-5.0-1.5-2.0$

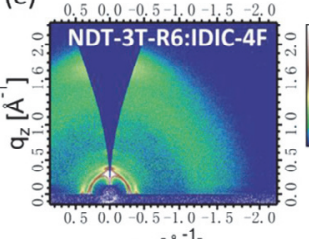

$q_{x y}\left[\AA^{-1}\right]$

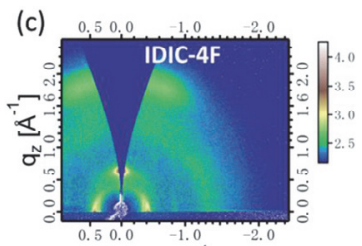

(f)

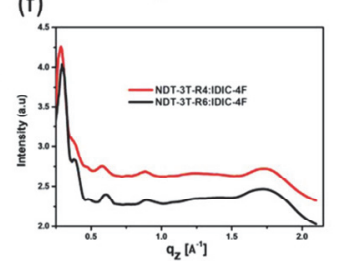

图 7 A: 48 (NDT-3T-R4):IDIC-4F 和 49 (NDT-3T-R6):IDIC-4F 混合膜的 AFM 相分离图像和 TEM 图像; B: (a $\sim e$ ) 单组分膜和混合膜的 2D GIWAXS 图案, (f) 混合膜的 GIWAXS 面外切割曲线. 版权 2018, WILEY-VCH ${ }^{[86]}$.

Figure 7 A: AFM phase images and TEM images of the 48 (NDT-3T -R4):IDIC-4F and 49 (NDT-3T-R6):IDIC-4F blended films; B: (a $\sim$ e) 2D GIWAXS patterns of the pure and blended films, (f) out-of-plane cuts of the GIWAXS patterns of the blended films. Copyright 2018, WILEY-VCH ${ }^{[86]}$.

在 DTBDT 小分子的设计中, 侧链调控同样是一种 提高电池性能有效的措施. 为了研究噻吩烷基链和噻吩 硫烷基链对给体材料结晶性的影响, Kwon 课题组 ${ }^{[97]}$ 设 计并合成了两个给体小分子, 以 DTBDT 为中心给体单 元, 罗丹宁为受体单元, 三联噻吩为 $\pi$ 桥, 不同的是, 小 分子 52 的给体单元侧链为噻吩烷基链, 小分子 $\mathbf{5 3}$ 的给 体单元侧链为噻吩硫烷基链(图 6). 相比小分子 52, S 原
子的引入增强了分子间的相互作用，小分子 $\mathbf{5 3}$ 的聚集 性和有序性增强，材料的结晶性更强，与受体小分子 O-IDTBR(图 11)混合后，虽然小分子 53 增强的结晶性增 加了混合膜中给体材料的空穴迁移率, 但也导致混合膜 更高程度的相分离，限制了激子成功扩散到界面，不利 于电荷分离，导致器件的短路电流和效率偏低，所以需 要调整给体材料的结晶性使混合膜获得合适的相分离.

表 3 二噻并苯并二噻吩类小分子电子给体材料在 ASM-OSCs 中的光伏性能

Table 3 Photovoltaic properties of DTBDT-based small molecule electron donors in ASM-OSCs

\begin{tabular}{|c|c|c|c|c|c|c|c|c|c|}
\hline Donor & HOMO/LUMO (eV) & $E_{\mathrm{g}}{ }^{a} / \mathrm{eV}$ & Acceptor & $\begin{array}{c}\mu_{\mathrm{h}} \times 10^{-4} / \\
\left(\mathrm{cm}^{2} \cdot \mathrm{V}^{-1} \cdot \mathrm{s}^{-1}\right)\end{array}$ & $V_{\mathrm{oc}} / \mathrm{V}$ & $J_{\mathrm{sc}} /\left(\mathrm{mA} \cdot \mathrm{cm}^{-2}\right)$ & $\mathrm{FF} / \%$ & $\mathrm{PCE} / \%$ & Reference \\
\hline 52 & $-5.11 /-3.43$ & 1.68 & O-IDTBR & 2.26 & 0.76 & 13.28 & 41.00 & 4.20 & [97] \\
\hline 53 & $-5.17 /-3.49$ & 1.68 & O-IDTBR & 2.97 & 0.78 & 8.07 & 43.00 & 2.72 & [97] \\
\hline 55 & $-5.35 /-3.51$ & 1.83 & Y6 & 0.778 & 0.852 & 23.03 & 65.43 & 12.84 & [98] \\
\hline 56 & $-5.34 /-3.50$ & 1.81 & Y6 & 1.52 & 0.854 & 24.69 & 70.06 & 14.78 & [98] \\
\hline 57 & $-5.32 /-3.53$ & 1.84 & IDIC-4Cl & 4.29 & 0.776 & 18.27 & 67.96 & 9.64 & [99] \\
\hline 59 & $-5.56 /-3.60$ & 1.87 & IDIC-4Cl & 5.62 & 0.885 & 19.78 & 68.81 & 12.05 & [99] \\
\hline 57 & $-5.32 /-3.53$ & 1.84 & IDIC-4Cl & 3.30 & 0.776 & 18.27 & 67.96 & 9.64 & [107] \\
\hline 57 & $-5.32 /-3.53$ & 1.84 & Y6 & 1.32 & 0.861 & 24.34 & 68.44 & 14.34 & [107] \\
\hline
\end{tabular}

${ }^{a}$ 由给体材料吸收光谱的最大吸收边计算得到: $E_{\mathrm{g}}=1240 / \lambda_{\text {max }}(\mathrm{nm})$. 
魏志祥课题组 ${ }^{[98]}$ 通过系统地移动中心 DTBDT 单元 上侧链烷基链的支点, 设计并合成了 $\mathrm{C} 1$ 支点的小分子 54、C2 支点的小分子 55 和 $\mathrm{C} 3$ 支点的小分子 56(图 6); 如 图 8A, 8B 所示, 由于分子间相互作用依次增强, 三个小 分子成膜后的结晶性依次增加, 且在与受体小分子 Y6 混合并进行热退火后, 三个给体小分子在混合膜中的结 晶度均得到提高, 小分子 55/Y6 和小分子 56/Y6 混合膜 显示出纳米纤维状的网络结构; 其中, 小分子 $\mathbf{5 6}$ 在其混 合膜中的结晶度最高, 而且与 Y6 混合形成了最明显的 纳米纤维状的多级次形貌, 即给体与受体混合的相区、 大给体相区以及给体的单晶区共同存在, 实现了激子分 离与电荷传输之间的平衡; 小分子 54、55 和 56 为基础 的器件 PCE 最高分别为 $11.79 \% 、 12.84 \%$ 和 $14.78 \%$. 这 项工作表明, 通过调节侧链支点位置可以改善材料的结 晶性和混合膜的形貌, 实现高效率的全小分子有机太阳 能电池.

另外, DTBDT 小分子中引入杂原子也可以实现对 材料结晶性的改善, 进而影响电池性能. 近期, 魏志祥 课题组 ${ }^{[99}$ 通过在中心核侧链上不引入杂原子、引入 $\mathrm{S}$ 原 子和 $\mathrm{S}$ 与 $\mathrm{Cl}$ 同时引入, 设计并合成了三种以 DTBDT 为 给体单元, 双噻吩为 $\pi$ 桥, 罗丹宁为端基的小分子, 分 别是小分子 57、58 和 59(图 6). $\mathrm{S}$ 和 $\mathrm{Cl}$ 原子的同时引入, 使得小分子 59 的材料拥有最高的结晶性和电荷迁移率; 三种给体小分子 57、58 和 59 分别与高结晶性的受体小 分子 IDIC-4Cl(图 11)混合并进行热退火和溶剂退火后, 均形成了双连续的纳米级互穿网络结构和 $3 \mathrm{D}$ 电荷传输
通道，器件都具有很好的光伏性能，效率分别为 $9.64 \%$ 、 10.81\%和 $12.05 \%$; 小分子 $\mathbf{5 9}$ 为基础的器件效率更高, 得益于混合膜中给体的结晶性最强和形成了最适中的 相分离形貌. 这项工作提供了一种潜在的有效策略，利 用氯原子和硫原子的协同效应，可以有效地设计出一种 高性能的 A-D-A 小分子给体，并用于制备高性能的全 小分子有机太阳能电池.

总之, 通过侧链调控和引入杂原子等措施可以有效 调控 DTBDT 分子的堆积取向和材料的结晶性, 进而获 得更好的混合膜形貌和电池性能. 目前, DTBDT 给体小 分子为基础的电池实现了全小分子电池的效率最高值; 由此可见，相比于 BDT 和 NDT，给体小分子中心共轭 单元的扩展是获得更高结晶性和光伏性能的一种有效 的分子设计思路.

\section{5 后处理工艺实现对材料结晶性和混合膜形貌 的调控}

除了分子本身的设计对材料结晶性有着重要的影 响之外, 后处理工艺可作为重新排列或增强共混物分子 堆积的补充，同样可以调控材料的结晶性和混合膜的形 貌，实现更好的电池性能. 例如热退火工艺(TA $)^{[100-101]}$ 、 溶剂退火 $(\mathrm{SVA})^{[102-104]}$ 和在活性层中加入添加剂[105-106]等 措施，其中, TA 和 SVA 是目前溶液加工非富勒烯体系全 小分子有机太阳能电池中普遍使用的方法.
A
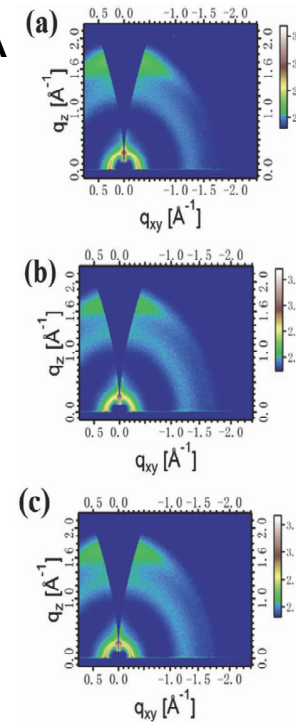
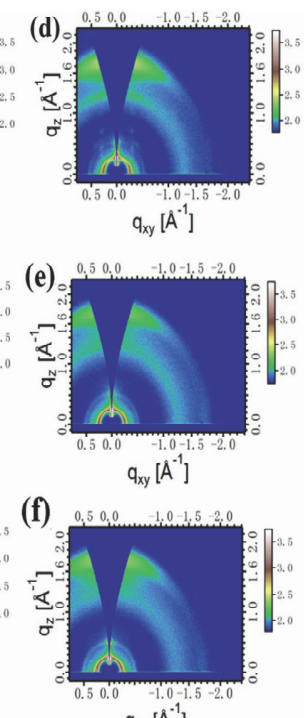

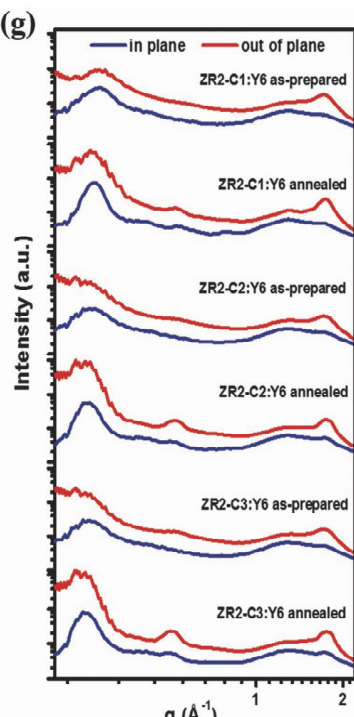

$q\left(\AA^{-1}\right)$ в
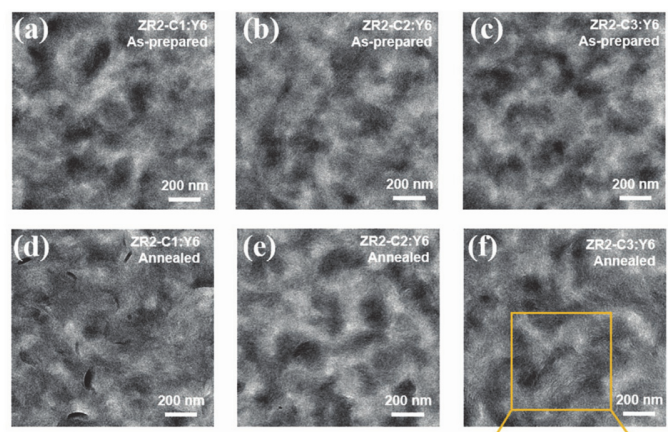

(h) First level: : side chains
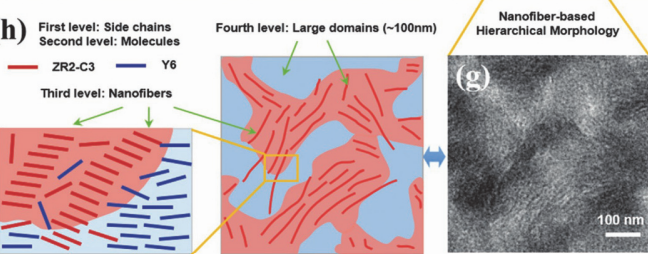

图 8 A: Y6 体系 BHJ 混合膜的 GIWAXS 数据; 无后处理的 54 (ZR2-C1:Y6)混合膜的 2D GIWAXS 图像, (d) 有后处理的; (b) 无后处理的 $\mathbf{5 5}$ (ZR2-C2:Y6)混合膜, (e) 有后处理的; (c) 无后处理的 56 (ZR2-C3:Y6), (f) 有后处理的; (g) 混合膜 2D GIWAXS 的面内面外切割曲线; B: (a) 无后 处理混合膜 54:Y6 的 TEM 图像, (d) 有后处理的; (b) 无后处理的混合膜 55:Y6, (e) 有后处理的; (c) 无后处理的混合膜 56:Y6, (f, g) 有后处理的; (h) 混合膜中多级次形貌的示意图. 版权 2020, Wiley-VCH GmbH ${ }^{[98]}$.

Figure 8 A: GIWAXS data for BHJ blend films in Y6 systems. Two-dimensional GIWAXS image of 54 (ZR2-C1:Y6) as-prepared and (d) after annealing; (b) 55 (ZR2-C2:Y6) as-prepared and (e) after annealing; (c) 56 (ZR2-C3:Y6) as-prepared and (f) after annealing; (g) in-plane patterns and out-of-plane patterns of two-dimensional GIWAXS of the blending films; B: (a) TEM images of 54:Y6 as-prepared and (d) after annealing; (b) 55:Y6 as-prepared and (e) after annealing; (c) 56:Y6 as-prepared and (f, g) after annealing. (h) Illustration of the hierarchical morphology in the blending films. Copyright 2020, Wiley-VCH GmbH ${ }^{[98]}$. 
为了研究热退火工艺对混合膜形貌的影响, 魏志祥 课题组 ${ }^{[107]}$ 报道了一种基于 DTBDT 的小分子给体 57(图 8), 以双噻吩为 $\pi$ 桥, 罗丹宁为受体单元; 如图 9A, 9B 所示, 小分子 57 拥有明显的分子平面性和紧密的分子 间堆积, 随后分别与受体小分子 Y6 和高结晶性的受体 小分子 IDIC-4Cl 形成混合膜, 小分子 $\mathbf{5 7}$ 与 IDIC-4Cl 为 活性层的器件在 $120{ }^{\circ} \mathrm{C}$ 下退火 $10 \mathrm{~min}$ 之后显示比无热 退火时更高的 PCE 为 $9.64 \%$; 小分子 $\mathbf{5 7}$ 与 Y6 为活性层 的器件在 $120{ }^{\circ} \mathrm{C}$ 下退火 $10 \mathrm{~min}$ 之后显示比无热退火时 (5.05\%)更明显增加的 PCE 为 $14.34 \%$; 这说明热退火工 艺极大地改善了活性层的形貌和器件的性能. 值得注意 的是, 之所以与 Y6 混合后的器件性能更高, 是因为混
合膜形成了多级次形貌，实现了大尺度给体相域、小分 子 57 单晶的出现和小尺度给体受体混合相域共存的状 态，很好地实现了混合膜中激子分离与电荷传输之间的 平衡，实现了高的短路电流和填充因子，所以实现了高 的 PCE. 因此, 通过热退火可以调控活性层的形貌例如 更好的相分离和多级次形貌等, 对获得高性能有机太阳 能电池具有重要作用.

为了研究溶剂退火工艺对混合膜形貌的影响, Kido 课题组 ${ }^{[108]}$ 报道了一种新型的给体小分子 45 (图 2), 以 $\mathrm{BDT}$ 为给体单元, 三噻吩为 $\pi$ 桥, 罗丹宁为受体单元, 受体材料为 O-IDTBR 小分子. 当对小分子 45/O-IDTBR 混合膜用二氯甲烷进行溶剂退火(SVA)之后，相比无处

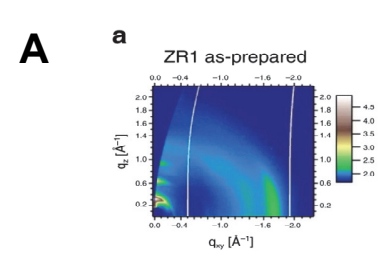

d $\quad \mathrm{ZR} 1+\mathrm{Y} 6110^{\circ} \mathrm{C}$

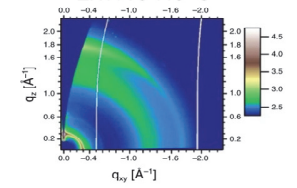

$\mathbf{h}$

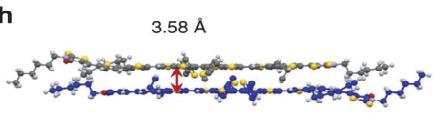

a

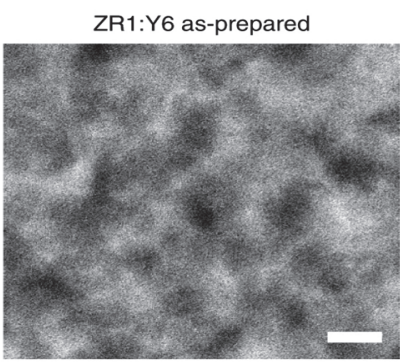

d

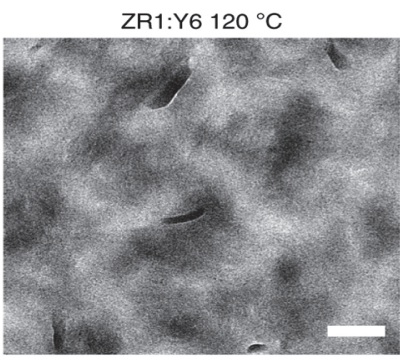

b $\quad$ ZR1 $120^{\circ} \mathrm{C}$

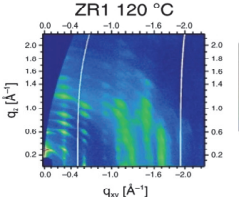

e $\quad Z R 1: Y 6120^{\circ} \mathrm{C}$

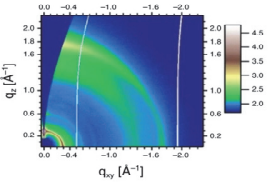

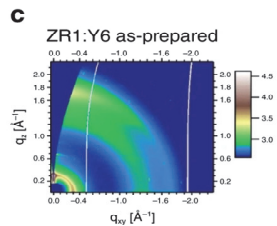

f $\quad$ ZR1:Y $6140^{\circ} \mathrm{C}$

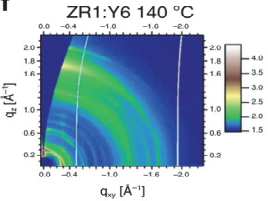

$\left(-1 A^{-1}\right.$
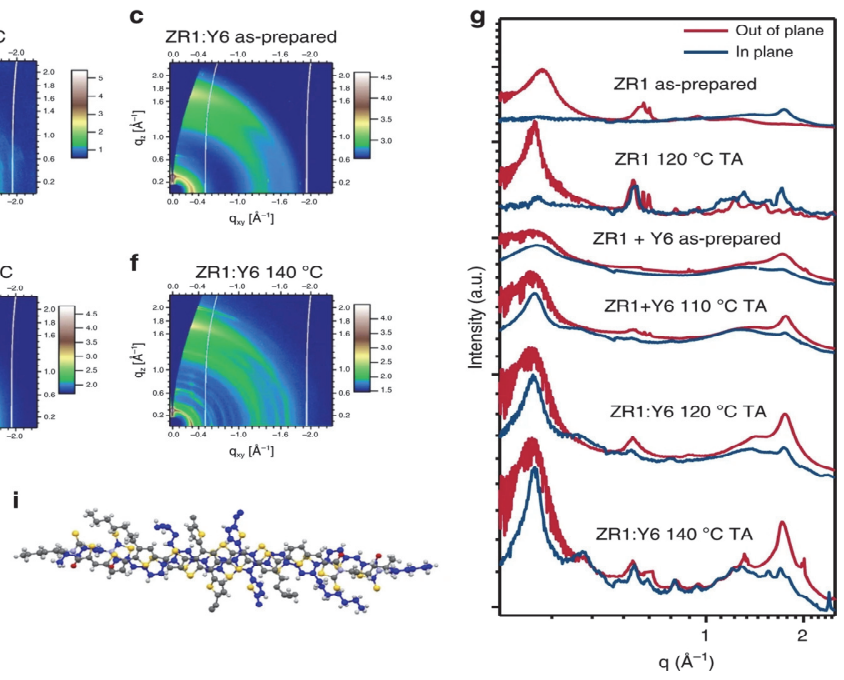

b

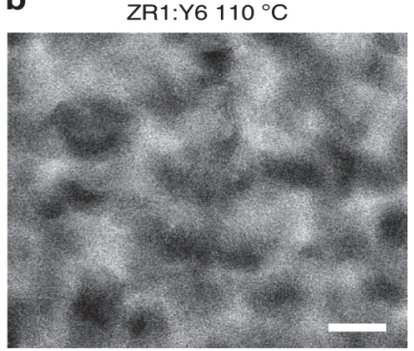

C ZR1:IDIC-4Cl as-prepared

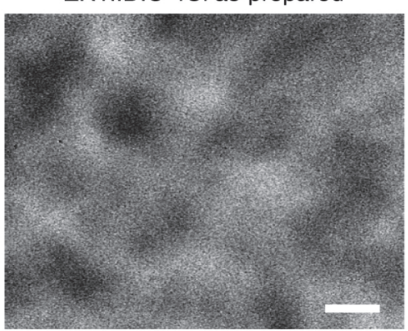

e

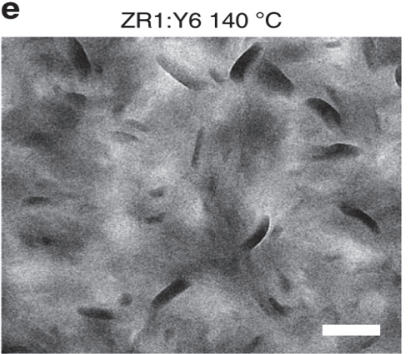

$\mathbf{f}$

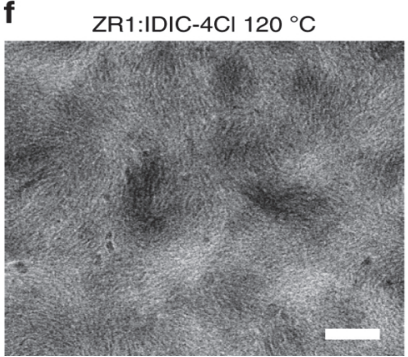

图 9 A: 单组分膜和混合膜的微观结构; $(\mathrm{a} \sim \mathrm{f})$ 单组分膜和混合膜的 2D GIWAXS 图案; (g) 相应的面内面外切割曲线; (h) 57 (ZR1)小分子在它的 单晶中垂直于二聚体的 $\pi$ 堆积的视图; (i) 沿着 $\pi$ 堆积方向; B: 57:Y6 和 57:IDIC-4Cl 混合膜的形貌分析; (a f f 混合膜在不同退火温度下的 TEM 图像, 其尺寸大都在 $200 \mathrm{~nm}$. 版权 2019, Springer Nature ${ }^{[107]}$.

Figure 9 A: Microstructures of pristine and blend films. (a $\sim$ f) 2D GIWAXS patterns of pristine and blend films; (g) Corresponding out-of-plane curves and in-plane curves; (h) View of perpendicular to $\pi$-stacking of dimers of 57 (ZR1) molecules in its single crystal and (i) along the $\pi$-stacking direction; B Morphology analysis of 57:Y6 and 57:IDIC-4Cl blends; $(\mathrm{a} \sim \mathrm{f}) \mathrm{TEM}$ images of blends films obtained at different annealing temperatures, and the scale bars are all $200 \mathrm{~nm}$. Copyright 2019, Springer Nature ${ }^{[107]}$. 
理时均匀光滑的表面形貌, 混合膜的粗糙度上升, 并且 膜中给体和受体材料的结晶性均提高, 尤其溶剂退火 $70 \mathrm{~s}$ 后的薄膜形成了更合适的相分离, 实现了电荷分离 与传输之间的平衡, 器件的短路电流和填充因子增大, PCE 由 4.30\%增加到 6.36\%. 由此可见, SVA 对非富勒烯 全小分子有机太阳能电池的光伏性能起着关键作用.

为了研究引入添加剂对混合膜形貌的影响, 陆仕荣 课题组 ${ }^{[15]}$ 在之前报道的小分子 23 (图 1) 与 Y6 的体系中 加入 $\mathrm{PC}_{71} \mathrm{BM}$ 添加剂, 使电池获得了更好的光伏性能. 如图 10 所示, 加入 $\mathrm{PC}_{71} \mathrm{BM}$ 后, 其与小分子 23 和 $\mathrm{Y} 6$ 均 具有好的混溶性, 活性层的结晶度提高且结晶取向由 edge-on 转变为更有利于电荷传输的 face-on 取向, 同时 形成了更有利于电荷分离与传输的相分离形貌和与激 子扩散长度相近的纯相域尺寸, 因此提高了电池的性 能; 尤其加入质量分数为百分之五的添加剂的体系, 在 没有牺牲开路电压和短路电流的前提下, 填充因子 $\mathrm{FF}$ 达到了 $77.11 \%, \mathrm{PCE}$ 高达 $15.34 \%$. 这项工作说明, 在电 池活性层中引入添加剂可以诱导出更好的活性层形貌, 对获得高性能有机太阳能电池具有重要作用.

由此, 通过热退火、溶剂退火和引入添加剂等方法 可以对混合膜的结晶性和形貌进行调控, 进而获得更好 的电池性能.

\section{6 总结与展望}

近几年来, NF-ASM OSCs 迅速发展起来, 并逐渐接 近聚合物有机太阳能电池的光伏效率, 电池性能不断提 升的关键来源于新型的 A-D-A 型给体小分子和稠环受 体小分子 ${ }^{[109]}$ 的开发和应用, 但是要实现 NF-ASM OSCs 的商业化仍有许多问题需要讨论和解决. 鉴于此, 我们 提出了几点建议:

(1)精确调控材料的结晶性: 相比于聚合物材料, 小
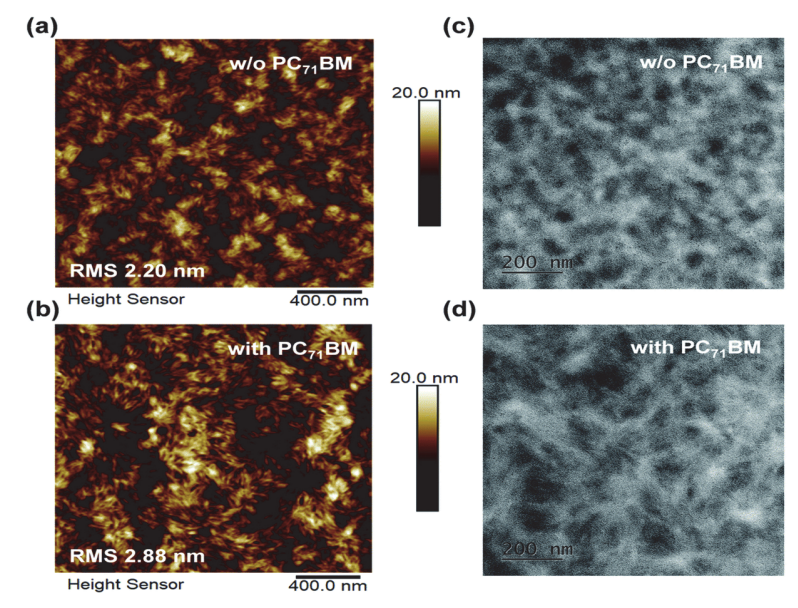

(d)

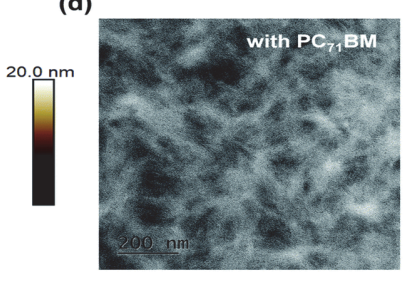

分子材料容易发生聚集造成过大的相区，有利于电荷传 输但不利于激子的分离, 影响了电池的性能. 通过对小 分子进行合理的设计，例如侧链、端基和 $\pi$ 桥设计等方 法，可以实现对材料结晶性的调控; 另外，为了增强材 料的结晶性, 可进一步扩展小分子的中心共轭单元, 例 如在 DTBDT 五元环的基础上, 发展七元环甚至九元环 为核或者连中间核的寡聚物分子，增加分子间的 $\mathrm{H}$ 聚 集, 增强材料的结晶性. 此外, 液晶材料是一种介于固 体和液体之间的有序流体，其拥有独特的液晶性质，通 过对液晶小分子进行合理的设计实现对其结晶能力的 精细调控也是一种获得高效率材料的有效措施.

(2)诱导优异的活性层形貌: 改善电池活性层形貌 以获得高性能的 NF-ASM OSCs 也是一大挑战. 电池活 性层的形貌主要由两个方面决定, 一是给体材料与受体 材料混合后直接形成的形貌, 这就要求选择合适的给体 与受体匹配, 在实现对太阳光谱强且宽的吸收以及合适 的能级匹配情况下，保证混合膜实现更合适的混溶性、 结晶性与相分离等; 二是对混合膜进行热退火、溶剂退 火和引入添加剂等后处理工艺, 以获得更好的纳米级互 穿网络结构和给受体结晶性, 实现薄膜中激子分离与电 荷传输之间的平衡, 进而获得好的光伏性能, 这就要求 活性层材料要具有好的稳定性和可调节性. 鉴于此, 应 探索系统且全面的 OPV 理论研究作为指导, 如机器学 习, 从分子动力学热力学等方面全面对分子进行解析, 实现对给受体物理化学性质和匹配性、结晶性等问题的 准确预测; 除此之外, 在全小分子有机太阳能电池中, 也可尝试三元或者四元等掺杂手段，进一步改善混合膜 的形貌和提高电池的光伏性能.

(3)降低材料的合成成本: 目前已报道的高效小分 子光伏材料大多存在着结构复杂、合成步骤繁多和产率 低等问题, 尤其是稠环电子小分子受体(如 IDIC, ITIC,

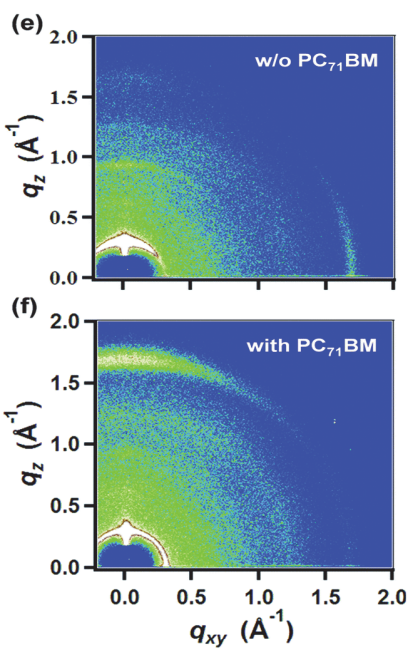

图 $10 \mathrm{AFM}$ 图像: $(2 \times 2 \mu \mathrm{m})$ (a) 膜里无 $\mathrm{PC}_{71} \mathrm{BM}$, (b) 膜内有 $\mathrm{PC}_{71} \mathrm{BM}$, 尺寸都是 $400 \mathrm{~nm}$; TEM 图像: (c) 膜没有 $\mathrm{PC}_{71} \mathrm{BM}$, (d) 膜有 $\mathrm{PC}_{71} \mathrm{BM}$, 尺寸 是 $200 \mathrm{~nm}$; 2D GIWAXS 图案: (e) 膜里无 $\mathrm{PC}_{71} \mathrm{BM}$, (f) 膜里有 $\mathrm{PC}_{71} \mathrm{BM}$. 版权 2020, 英国皇家化学学会 ${ }^{[15]}$.

Figure 10 AFM images $(2 \times 2 \mu \mathrm{m})$ of (a) film w/o $\mathrm{PC}_{71} \mathrm{BM}$, and (b) film with $\mathrm{PC}_{71} \mathrm{BM}$; the scale bars are $400 \mathrm{~nm}$; TEM images of (c) film w/o PC $\mathrm{C}_{71} \mathrm{BM}$, and (d) film with $\mathrm{PC}_{71} \mathrm{BM}$, the scale bars are $200 \mathrm{~nm}$; $2 \mathrm{D}$ GIWAXS patterns of (e) film w/o $\mathrm{PC}_{71} \mathrm{BM}$, and (f) film with $\mathrm{PC}_{71} \mathrm{BM}$. Copyright 2020, The Royal Society of Chemistry ${ }^{[15]}$. 


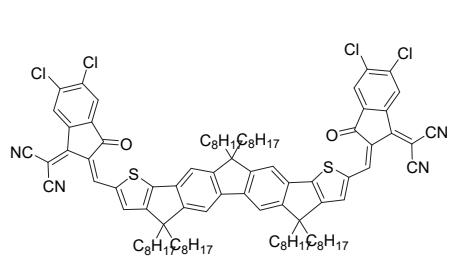

$\mathrm{F}-2 \mathrm{CI}$

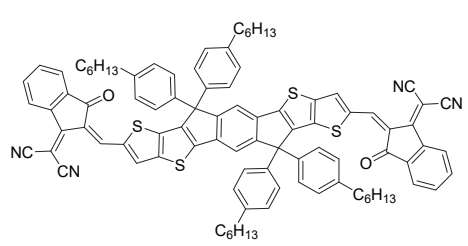

ITIC

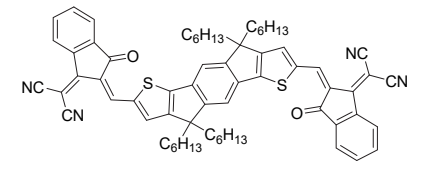

IDIC

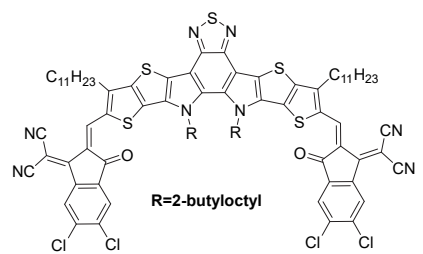

BO-4CI

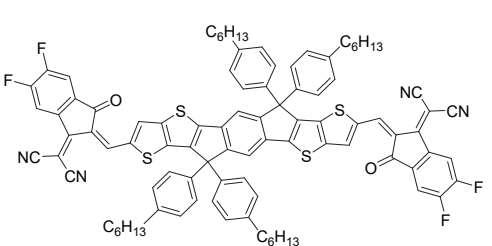

IT-4F

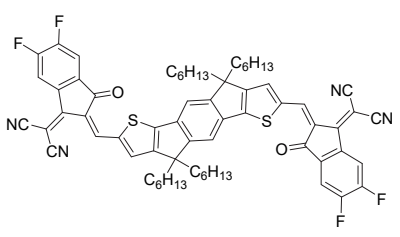

IDIC-4F

Y6
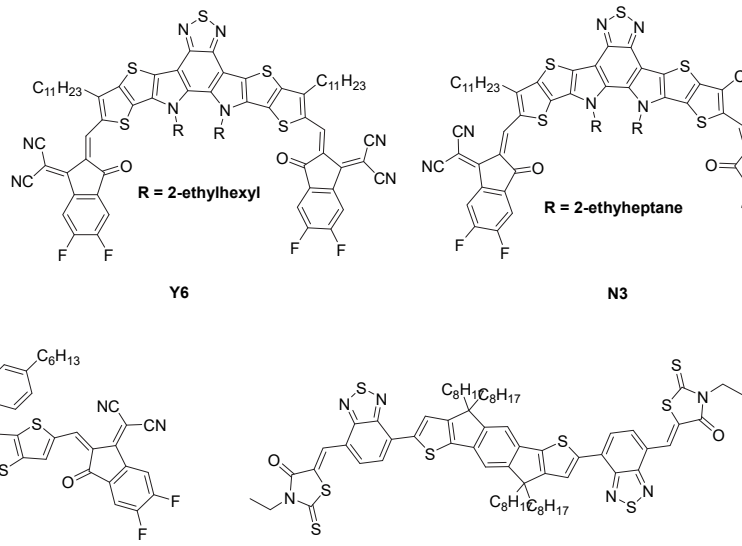

O-IDTBR

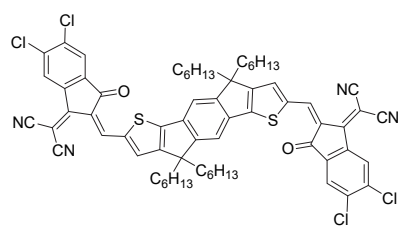

IDIC-4CI

图 11 本综述中介绍到的小分子受体材料的化学结构

Figure 11 Chemical structures of small molecule acceptors introduced in this review

Y6 等)的合成, 虽然小分子给体材料常用的合成反应产 率较高(如 Stille 偶联反应, Knoevenagel 缩合反应), 但在 材料成本上也很难满足商业应用的需求, 因此开发低成 本高效率的有机光伏材料是全小分子有机太阳能电池 走向应用的关键. 对此, 可尝试开发结构更简单的分子 和简化的合成方法, 使用低成本的原材料, 使合成步骤 控制在三步之内; 开发新型的提纯装置代替常用的柱层 析分离方法, 减少对产物的浪费, 提高产率.

(4)简化器件的加工工艺: 目前全小分子有机太阳 能电池的制备过程比较繁琐, 尤其是对活性层进行后处 理等工艺的引入, 使得加工成本较高且器件效率的可重 复性较差, 对此, 未来应探索无后处理和额外电荷传输 层的高效全小分子有机太阳能电池, 简化器件的加工工 艺; 另外, 尝试将程序化机器操作引入器件的制备中, 定量均匀地控制旋涂薄膜时的滴加速度以及基板的转 速等条件, 减少人为因素, 提高器件光伏效率的可重复 性; 同时, 减少环境污染至关重要, 在器件加工过程中, 应大力发展使用绿色溶剂进行加工, 减少卤代试剂的使 用, 例如使用四氢呋喃等绿色溶剂; 此外, 为了电池的 商业化应用, 大面积和厚膜器件的探索非常重要, 在大 面积器件中, 可采用狭缝涂覆技术或卷对卷工艺代替传 统的旋涂技术, 实现柔性基底的有效涂覆并极大地减少 了材料的浪费, 在厚膜器件中, 为了解决薄膜加厚之后 填充因子和短路电流下降的问题, 可尝试在二元全小分 子厚膜器件中引入结晶性强的第三组分聚合物或小分 子, 进一步调控混合膜的形貌, 实现光伏性能的保持或
提升. 因此, 探索效率高且可重复性性好的大面积及厚 膜器件是一个重要方向.

(5)提高器件的稳定性: 目前的全小分子电池对器 件加工条件和储存环境如湿度、热、光和氧气等比较敏 感, 在空气中光伏性能下降较快, 所以提高器件稳定性 是实现商业化的一大要求. 首先, 可通过提高给体材料 的稳定性来提升电池中活性层的稳定性, 可尝试调节给 体材料结晶性或在给体小分子结构中引入抗氧化基团 和刚性侧链等方法提高其稳定性. 也可尝试提高受体材 料的稳定性, 以往研究发现非富勒烯稠环电子受体比富 勒烯受体拥有更好的光热和光伏性能稳定性, 由于非富 勒烯受体的结晶性很高, 在混合膜中容易形成高度聚集 状态影响混合膜的稳定性, 可尝试在稠环电子受体中引 入非稠环单元降低其结晶性，可能有利于材料稳定性的 提升. 同时, 提高界面层材料的稳定性也至关重要, 目 前全小分子器件普遍使用的空穴传输层为 PEDOT:PSS, 电子传输层有 $\mathrm{LiF}, \mathrm{ZnO}$ 和 $\mathrm{Ca}$, 这些常用的界面层材料 对环境的湿度等比较敏感造成器件稳定性下降, 可尝试 对 PEDOT:PSS 进行掺杂, 例如引入全氟磺酸树脂 (Nafion)等稳定性好的材料, 也可尝试使用稳定性高的 金属氧化物和聚合物作为电子传输层, 进一步提升器件 的稳定性.

基于以上因素，未来，全小分子有机太阳能电池若 能充分结合非富勒烯受体小分子和给体小分子的优势, 实现优异的光伏性能并克服成本和稳定性问题, 将有希 望实现商业化应用. 


\section{作者简介}

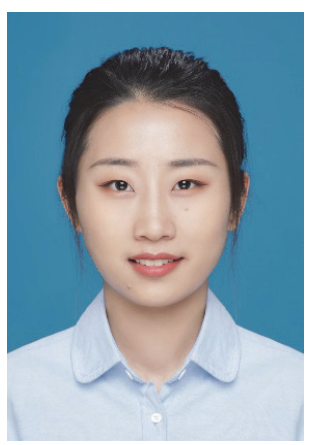

吕敏, 硕士研究生. 2019 年 6 月于青岛科技大学材料科学 与工程学院新能源材料与器件专业取得学士学位, 同年 9 月 进入国家纳米科学中心魏志祥研究员课题组开展硕士研究工 作. 目前其主要的研究方向为小分子给体材料的设计与合成, 主要研究高结晶性小分子给体材料应用于非富勒烯全小分子 有机太阳能电池中对形貌调控的影响.

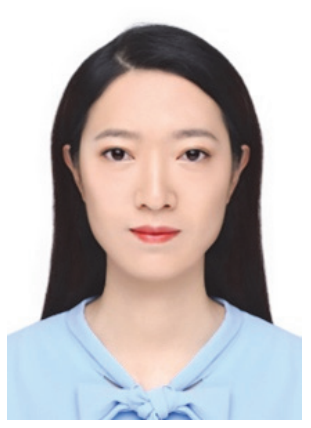

周瑞敏, 2015 年本科毕业于河南大学化学实验班, 自 2015 年 9 月进入国家纳米科学中心(中国科学院大学中丹学院) 硕博连读, 研究方向主要是可溶性有机光伏小分子给体的设 计合成与器件制备研究. 目前发表的文章包括 Nature Communications 一篇, Advanced Functional Materials 一篇等.

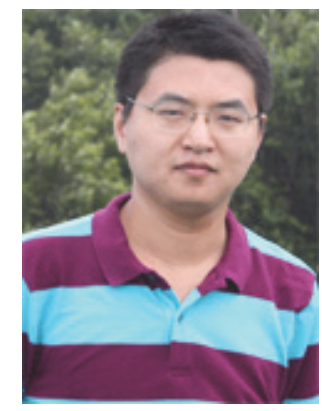

吕琨, 国家纳米科学中心研究员, 博士生导师. 2004 年 7 月毕业于山东大学化学与化工学院, 获得学士学位; 2009 年 12 月于中国科学院化学研究所获得博士学位; 2010 年 1 月至 今, 任职国家纳米科学中心研究员. 研究重点是用于光伏器 件的聚合物和小分子半导体材料的合成及其在大面积柔性器 件中的应用. 基于以上研究, 发表了90 多篇论文, 被引用超 过 2000 次; 并且获得了中国化学会青年化学奖、北京市科技 新星计划、中国科学院青年创新促进会优秀会员和国家优秀 青年科学基金等基金支持.

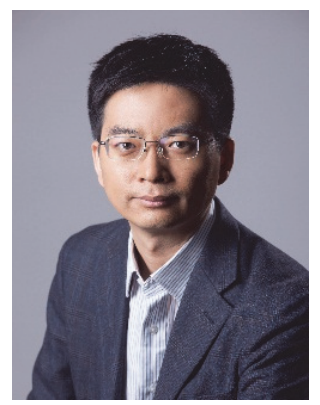

魏志祥, 国家纳米科学中心研究员, 博士生导师. 1997 和 2000 年分别在西安交通大学获得学士和硕士学位, 2003 年中 国科学院化学研究所获得博士学位. 之后分别在德国马普胶 体界面研究所和多伦多大学从事博士后研究. 2006 年加入国 家纳米中心工作. 主要研究领域为有机光电功能纳米材料与 柔性器件, 研究通过自组装方法制备结构和性能可控的有机 光电功能纳米材料, 并探索其在手性传感器件、太阳能电池和 储能器件等柔性器件中的应用.

\section{References}

[1] Yu, G.; Gao, J.; Hummelen, J. C.; Wudl, F.; Heeger, A. J. Science 1995, 270, 1789.

[2] Sariciftci, N. S.; Braun, D.; Zhang, C.; Srdanov, V. I.; Heeger, A. J.; Stucky, G.; Wudl, F. Appl. Phys. Lett. 1993, 62, 585.

[3] Zhao, J.; Li, Y.; Yang, G.; Jiang, K.; Lin, H.; Ade, H.; Ma, W.; Yan, H. Nat. Energy 2016, $1,15027$.

[4] Suman; Singh, S. P. J. Mater. Chem. A 2019, 7, 22701.

[5] He, C.; Hou, J. H. Acta Phys.-Chim. Sin. 2018, 34, 1202 (in Chinese). (何畅, 侯剑辉, 物理化学学报, 2018, 34, 1202)

[6] Deng, Y. H.; Peng, A. D.; Wu, X. X.; Chen, H. J.; Huang, H. Acta Phys.-Chim. Sin. 2019, 35, 461 (in Chinese). (邓神华, 彭爱东, 吴 䈗曦, 陈华杰, 黄辉, 物理化学学报, 2019, 35, 461.)

[7] Dai, S. X.; Zhao, F. W.; Zhang, Q. Q.; Lau, T. K.; Li, T. F.; Liu, K.; Ling, Q. D.; Wang, C. R.; Lu, X. H.; You, W.; Zhan, X. W. J. Am. Chem. Soc. 2017, 139, 1336.

[8] Fu, Y.; Wang, F.; Zhang, Y.; Fang, X.; Lai, W. Y.; Huang, W. Acta Chim. Sinica 2014, 72, 158 (in Chinese). (付钰, 主芳, 张燕, 方旭, 赖文勇, 黄维, 化学学报, 2014, 72, 158.)

[9] Cheng, P.; Li, G.; Zhan, X. W.; Yang, Y. Nat. Photonics 2018, 12, 131.

[10] Yan, C. Q.; Barlow, S.; Wang, Z. H.; Yan, H.; Jen, A. K. Y.; Marder, S. R.; Zhan, X. W. Nat. Rev. Mater. 2018, 3, 18003.

[11] Zhang, Z. H.; Guang, S.; Yu, J. S.; Wang, H. T.; Cao, J. R.; Du, F. Q.; Wang, X. L.; Tang, W. H. Sci. Bull. 2020, 65, 1533.

[12] Huang, H.; Li, X. J.; Sun, C. K.; Angunawela, I.; Qiu, B. B.; Du, J. Q.; Qin, S. C.; Meng, L.; Zhang, Z. J.; Ade, H.; Li, Y. F. J. Mater Chem. C 2020, 8, 7718.

[13] Lin, F.; Jiang, K.; Kaminsky, W.; Zhu, Z.; Jen, A. K. Y. J. Am. Chem. Soc. 2020, 142, 15246.

[14] Lin, Y.; Firdaus, Y.; Isikgor, F. H.; Nugraha, M. I.; Yengel, E.; Harrison, G. T.; Hallani, R.; El-Labban, A.; Faber, H.; Ma, C.; Zheng, X.; Subbiah, A.; Howells, C. T.; Bakr, O. M.; McCulloch, I.; Wolf, S. D.; Tsetseris, L.; Anthopoulos, T. D. ACS Energy Lett. 2020, 5, 2935.

[15] Hu, D. Q.; Yang, Q. G.; Chen, H. Y.; Wobben, F.; Le Corre, V. M.; Singh, R.; Liu, T.; Ma, R. J.; Tang, H.; Koster, L. J. A.; Duan, T. N.; Yan, H.; Kan, Z. P.; Xiao, Z. Y.; Lu, S. R. Energy Environ. Sci. 2020, $13,2134$.

[16] Pradhan, R.; Malhotra, P.; Gupta, G.; Singhal, R.; Sharma, G. D.; Mishra, A. ACS Appl. Mater. Interfaces 2020, 12, 41869.

[17] Lin, Y. Z.; Li, Y. F.; Zhan, X. W. Chem. Soc. Rev. 2012, 41, 4245.

[18] Lin, Y. Z.; Zhan, X. W. Acc. Chem. Res. 2016, 49, 175.

[19] Wan, X. J.; Li, C. X.; Zhang, M. T.; Chen, Y. S. Chem. Soc. Rev. $\mathbf{2 0 2 0}, 49,2828$.

[20] Wu, H.; Fan, H. J.; Xu, S. J.; Ye, L.; Guo, Y.; Yi, Y. P.; Ade, H.; Zhu, X. Z. Small 2019, 15, 1902656

[21] Yue, Q. H.; Wu, H.; Zhou, Z. C.; Zhang, M.; Liu, F.; Zhu, X. Z. Adv. 
Mater. 2019, 31, 1904283.

[22] Zhou, Z. C.; Xu, S. J.; Song, J. N.; Jin, Y. Z.; Yue, Q. H.; Qian, Y. H.; Liu, F.; Zhang, F. L.; Zhu, X. Z. Nat. Energy 2018, 3, 952.

[23] Hou, R.; Li, M.; Ma, X. Q.; Huang, H.; Lu, H.; Jia, Q. Q.; Liu, Y. H.; $\mathrm{Xu}, \mathrm{X}$. J.; Li, H. B.; Bo, Z. S. ACS Appl. Mater. Interfaces 2020, 12, 46220.

[24] Feng, S. F.; Tang, N. N.; Wang, X. D.; Huang, H.; Ran, G. L.; Liu, Y. H.; Xie, Z. Q.; Zhang, W. K.; Bo, Z. S. ACS Appl. Mater. Interfaces 2020, 12, 4638.

[25] Sun, R.; Wu, Y.; Guo, J.; Luo, Z. H.; Yang, C. L.; Min, J. Sci. China: Chem. 2020, 63, 1246.

[26] Kan, B.; Chen, X. B.; Gao, K.; Zhang, M.; Lin, F; Peng, X. B. Nat. Energy 2020, 67, 104209.

[27] Nian, L; Kan, Y. Y.; Gao, K.; Zhang, M.; Li, N.; Zhou, G. Q.; Jo, S. B.; Shi, X. L.; Lin, F; Rong, Q. K.; Liu, F.; Zhou, G. F.; Jen, A. K.-Y. Joule 2020, 4, 2223.

[28] Su, W. S.; Fan, Q. P.; Guo, X.; Meng, X. Y.; Bi, Z. Z.; Ma, W.; Zhang, M. J.; Li, Y. F. Nat. Energy 2017, 38, 510.

[29] Tang, H.; Xu, T. L.; Yan, C. Q.; Gao, J.; Yin, H.; Lv, J.; Singh, R.; Kumar, M.; Duan, T. N.; Kan, Z. P.; Lu, S. R.; Li, G. Adv. Sci. 2019 , 6, 1901613.

[30] Ge, J. F.; Wei, Q.; Peng, R. X.; Zhou, E. J.; Yan, T. T.; Song, W.; Zhang, W. X.; Zhang, X. A.; Jiang, S. L.; Ge, Z. Y. ACS Appl. Mater. Interfaces 2019, 11, 44528 .

[31] Tang, H.; Chen, H. Y.; Yan, C. Q.; Huang, J. M.; Fong, P. W.; Lv, J.; Hu, D. Q.; Singh, R.; Kumar, M.; Xiao, Z. Y.; Kan, Z. P.; Lu, S. R.; Li, G. Adv. Energy Mater. 2020, 10, 2001076.

[32] Gao, K.; Jo, S. B.; Shi, X. L.; Nian, L.; Zhang, M.; Kan, Y. Y.; Lin, F.; Kan, B.; Xu, B.; Rong, Q. K.; Shui, L. L.; Liu, F.; Peng, X. B.; Zhou, G. F.; Cao, Y.; Jen, A. K.-Y. Adv. Mater. 2019, 31, 1807842.

[33] Du, B. C.; Yi, J. C.; Yan, H.; Wang, T. Chem. Eur. J. 2020, 26, 1.

[34] Zhao, F. W.; Wang, C. R.; Zhan, X. W. Adv. Energy Mater. 2018, 8, 1703147.

[35] Yang, Y.; Lin, F. Y.; Zhu, C. T.; Chen, T.; Ma, S. P.; Luo, Y.; Zhu, L.; Guo, X. Y. Acta Chim. Sinica 2020, 78, 217 (in Chinese). (杨英, 林 飞宇, 朱从潭, 陈甜, 马书鹏, 罗媛, 朱刘, 郭学益, 化学学报, 2020, 78, 217.)

[36] Huo, Y.; Zhang, H. L.; Zhan, X. W. ACS Energy Lett. 2019, 4, 1241.

[37] Ren, J.; Sun, M. L. Chin. J. Org. Chem. 2016, 36, 2284 (in Chinese). (任静, 孙明亮, 有机化学, 2016, 36, 2284.)

[38] Deng, D.; Zhou, E. J.; Wei, Z. X. Acta Phys.-Chim. Sin. 2018, 34, 1239 (in Chinese). (邓丹, 周二军, 魏志祥, 物理化学学报, 2018, 34, 1239.)

[39] Xie, L.; Yang, C.; Zhou, R. M.; Wang, Z.; Zhang, J. Q.; Lu, K.; Wei, Z. X. Chin. J. Chem. 2020, 38, 935.

[40] Sun, Y. N.; Gao, H. H.; Zhang, Y. M.; Wang, Y. C.; Kan, B.; Wan, X. J.; Zhang, H. T.; Chen, Y. S. Chin. J. Org. Chem. 2018, 38, 228.

[41] Wang, W. X.; Wang, J. Q.; Zheng, Z.; Hou, J. H. Acta Chim. Sinica 2020, 78, 382 (in Chinese). (王文璇, 王建邱, 郑众, 侯剑辉, 化学 学报, 2020, 78, 382.)

[42] Zhang, S. Q.; Qin, Y. P.; Zhu, J.; Hou, J. H. Adv. Mater. 2018, 30, 1800868.

[43] Tang, A. L.; Zhang, Q. Q.; Du, M. Z.; Li, G. Q.; Geng, Y. F.; Zhang, J. Q.; Wei, Z. X.; Sun, X. N.; Zhou, E. J. Macromolecules 2019, 52, 6227.

[44] Cui, Y.; Yao, H. F.; Zhang, J. Q.; Zhang, T.; Wang, Y. M.; Hong, L.; Xian, K. H.; Xu, B. W.; Zhang, S. Q.; Peng, J.; Wei, Z. X.; Gao, F.; Hou, J. H. Nat. Commun. 2019, 10, 2515.

[45] Jiang, H. X.; Li, X. M.; Wang, H.; Huang, G. Y.; Chen, W. C.; Zhang, R.; Yang, R. Q. ACS Appl. Mater. Interfaces 2020, 12, 26286.

[46] Liu, Q.; Jiang, Y.; Jin, K.; Qin, J.; Xu, J.; Li, W.; Xiong, J.; Liu, J.; Xiao, Z.; Sun, K.; Yang, S.; Zhang, X.; Ding, L. Sci. Bull. 2020, 65, 272.

[47] Bin, H. J.; Yang, Y. K.; Zhang, Z. G.; Ye, L.; Ghasem, M.; Chen, S. S.; Zhang, Y. D.; Zhang, C. F.; Sun, C. K.; Xue, L. W.; Yang, C. D.; Ade, H.; Li, Y. F. J. Am. Chem. Soc. 2017, 139, 5085.

[48] Guo, J.; Bin, H. J.; Wang, W.; Chen, B. C.; Guo, J.; Sun, R.; Zhang, Z. G.; Jiao, X. C.; Li, Y. F.; Min, J. J. Mater. Chem. A 2018, 6, 15675 .

[49] Zhang, S. Q.; Yang, L. Y.; Liu, D. L.; He, C.; Zhang, J. Q.; Zhang, Y.; Hou, J. H. Sci. China: Chem. 2017, 60, 1340.

[50] Cheng, X. F.; Li, M. M.; Guo, Z. Q.; Yu, J. D.; Lu, G. H.; Bu, L. J.; Ye, L.; Ade, H.; Chen, Y. S.; Geng, Y. H. J. Mater. Chem. A 2019, 7, 23008.

[51] Qin, J. Z.; An, C. B.; Zhang, J. Q.; Ma, K. C. Q.; Yang, Y.; Zhang, T.; Li, S. S.; Xian, K. H.; Cui, Y.; Tang, Y. B.; Ma, W.; Yao, H. F.;
Zhang, S. Q.; Xu, B. W.; He, C.; Hou, J. H. Sci. China Mater. 2020, $63,1142$.

[52] Adil, M. A.; Zhang, J. Q.; Deng, D.; Wang, Z.; Yang, Y.; Wu, Q.; Wei, Z. X. ACS Appl. Mater. Interfaces 2018, 10, 1526.

[53] Qiu, B. B.; Chen, Z.; Qin, S. C.; Yao, J.; Huang, W. C.; Meng, L.; Zhu, H. M.; Yang, Y.; Zhang, Z. G.; Li, Y. F. Adv. Mater. 2020, 32, 1908373.

[54] Ge, J. F.; Xie, L. C.; Peng, R. X.; Fanady, B.; Huang, J. M.; Song, W.; Yan, T. T.; Zhang, W. X.; Ge, Z. Y. Angew. Chem., Int. Ed. 2020, 59, 2808.

[55] Bin, H. J.; Angunawela, I.; Qiu, B. B.; Colberts, F. J. M.; Li, M. M.; Dyson, M. J.; Wienk, M. M.; Ade, H.; Li, Y. F.; Janssen, R. A. J. Adv. Energy Mater. 2020, 10, 2001589

[56] Liu, C. Y.; Qiu, N. L.; Sun, Y. N.; Ke, X.; Zhang, H. T.; Li, C. X.; Wan, X. J.; Chen, Y. S. Front. Chem. 2020, 8, 329.

[57] Chen, H. Y.; Hu, D. Q.; Yang, Q. G.; Gao, J.; Fu, J. H.; Yang, K.; He, H.; Chen, S. S.; Kan, Z. P.; Duan, T. N.; Yang, C.; Ouyang, J. Y.; Xiao, Z. Y.; Sun, K.; Lu, S. R. Joule 2019, 3, 3034

[58] Lin, Y. Z.; Zhao, F. W.; Wu, Y.; Chen, K.; Xia, Y. X.; Li, G. W.; Prasad, S. K. K.; Zhu, J. S.; Huo, L. J.; Bin, H. J.; Zhang, Z. G.; Guo, X.; Zhang, M. J.; Sun, Y. M.; Gao, F.; Wei, Z. X.; Ma, W.; Wang, C. R.; Hodgkiss, J.; Bo, Z. S.; Inganas, O.; Li, Y. F.; Zhan, X. W. Adv. Mater. 2017, 29, 1604155.

[59] Guo, J.; Balakirev, D. O.; Gu, C. J.; Peregudova, S. M.; Ponomarenko, S. A.; Liu, Z. T.; Luponosov, Y. N.; Min, J.; Lei, A W. Dyes Pigm. 2020, 175, 108078.

[60] Meng, W.; Lv, J.; Duan, T. N.; Kan, Z. P.; Lu, S. R.; Dai, X. X.; Li, Z. F. Mater. Chem. Phys. 2020, 247, 122874

[61] Bin, H. J.; Yao, J.; Yang, Y. K.; Angunawela, I.; Sun, C. K.; Gao, L.; Ye, L.; Qiu, B. B.; Xue, L. W.; Zhu, C. H.; Yang, C. H.; Zhang, Z. G.; Ade, H.; Li, Y. F. Adv. Mater. 2018, 30, 1706361

[62] Wu, Q.; Deng, D.; Zhou, R. M.; Zhang, J. Q.; Zou, W. J.; Liu, L. X.; Wu, S. H.; Lu, K.; Wei, Z. X. ACS Appl. Mater. Interfaces 2020, 12, 25100 .

[63] Yang, L. Y.; Zhang, S. Q.; He, C.; Zhang, J. Q.; Yang, Y.; Zhu, J.; Cui, Y.; Zhao, W. C.; Zhang, H.; Zhang, Y.; Wei, Z. X.; Hou, J. H. Chem. Mater. 2018, 30, 2129.

[64] Duan, T. N.; Tang, H.; Liang, R. Z.; Lv, J.; Kan, Z. P.; Singh, R.; Kumar, M.; Xiao, Z. Y.; Lu, S. R.; Laquai, F. J. Mater. Chem. A 2019, 7, 2541.

[65] Fang, J.; Ye, C. N.; Wang, X. H.; Wang, Y. L.; Guo, X.; Fan, Q. P.; Ma, W.; Zhang, M. J. Org. Electron. 2019, 67, 175.

[66] Huo, Y.; Gong, X. T.; Lau, T. K.; Xiao, T.; Yan, C. Q.; Lu, X. H.; Lu, G. H.; Zhan, X. W.; Zhang, H. L. Chem. Mater. 2018, 30, 8661.

[67] Dong, X. Y.; Yang, K.; Tang, H.; Hu, D. Q.; Chen, S. S.; Zhang, J.; Kan, Z. P.; Duan, T. N.; Hu, C.; Dai, X. X.; Xiao, Z. Y.; Sun, K.; Lu, S. R. Sol. RRL. 2020, 4, 1900326.

[68] Gao, J.; Ge, J. F.; Peng, R. X.; Liu, C.; Cao, L.; Zhang, D. L.; Fanady, B.; Hong, L.; Zhou, E. J.; Ge, Z. Y. J. Mater. Chem. A 2020, 8,7405 .

[69] Zhu, X. W.; Lu, K.; Li, H.; Zhou, R. M.; Wei, Z. X. Chin. Chem. Lett. 2016, 27, 1271.

[70] Takimiya, K.; Osaka, I. Chem. Rec. 2015, 15, 175.

[71] Loser, S.; Bruns, C. J.; Miyauchi, H.; Ortiz, R. P.; Facchetti, A.; Stupp, S. I.; Marks, T. J. J. Am. Chem. Soc. 2011, 133, 8142.

[72] Jiang, Z. Y.; Li, H.; Wang, Z.; Zhang, J. Q.; Zhang, Y. J.; Lu, K.; Wei, Z. X. Macromol. Rapid Commun. 2018, 39, 1700872.

[73] Kim, Y. J.; Cheon, Y. R.; Jang, J. W.; Kim, Y. H.; Park, C. E. J. Mater. Chem. C 2015, 3, 1904.

[74] Lee, J.; Ko, H.; Song, E.; Kim, H. G.; Cho, K. ACS Appl. Mater Interfaces 2015, 7, 21159.

[75] Lin, Y. R.; Chen, X. F.; Jiang, C. L.; Zhao, M. Z.; Li, Y. F.; Wang, H. Q. Org. Electron. 2018, 61, 197.

[76] Lobert, M.; Mishra, A.; Uhrich, C.; Pfeiffer, M.; Bauerle, P. J. Mater. Chem. C 2014, 2, 4879.

[77] Peng, Q.; Huang, Q.; Hou, X. B.; Chang, P. P.; Xu, J.; Deng, S. J. Chem. Commun. 2012, 48, 11452.

[78] Bagde, S. S.; Park, H.; Han, J. G.; Li, Y.; Ambade, R. B.; Ambade, S. B.; Kim, B.; Lee, S. H. Dyes Pigm. 2017, 137, 117.

[79] Bagde, S. S.; Park, H.; Tran, V. H.; Lee, S. H. Dyes Pigm. 2019, 163 , 30.

[80] Dutta, P.; Yang, W.; Eom, S. H.; Lee, W. H.; Kang, I. N.; Lee, S. H. Chem. Commun. 2012, 48, 573.

[81] Xia, C. C.; Wu, H.; Fan, H. J.; Shui, L. L.; Zhu, X. Z. J. Mater Chem. C 2020, 8, 7561.

[82] Dutta, P.; Yang, W.; Lee, W.-H.; Kang, I. N.; Lee, S.-H. J. Mater. 
Chem. 2012, 22, 10840.

[83] Li, H.; Fang, J.; Zhang, J. Q.; Zhou, R. M.; Wu, Q.; Deng, D.; Adil, M. A.; Lu, K.; Guo, X. F.; Wei, Z. X. Mater. Chem. Front. 2018, 2, 143.

[84] Li, H.; Zhao, Y. F.; Fang, J.; Zhu, X. W.; Xia, B. Z.; Lu, K.; Wang, Z.; Zhang, J. Q.; Guo, X. F.; Wei, Z. X. Adv. Energy Mater. 2018, 8, 1702377.

[85] Lin, Y. Z.; Wang, J. Y.; Zhang, Z. G.; Bai, H. T.; Li, Y. F.; Zhu, D. B.; Zhan, X. W. Adv. Mater. 2015, 27, 1170.

[86] Li, H.; Wu, Q.; Zhou, R. M.; Shi, Y. N.; Yang, C.; Zhang, Y. J.; Zhang, J. Q.; Zou, W. J.; Deng, D.; Lu, K.; Wei, Z. X. Adv. Energy. Mater. 2019, 9, 1803175.

[87] Shi, Y. A.; Yang, C.; Li, H.; Liu, L. X.; Zhou, R. M.; Zou, W. J.; Wang, Z.; Wu, Q.; Deng, D.; Zhang, J. Q.; Lu, K.; Wei, Z. X. Chin. Chem. Lett. 2019, 30, 906.

[88] Wu, Y.; Li, Z. J.; Guo, X.; Fan, H. L.; Huo, L. J.; Hou, J. H. J. Mater. Chem. 2012, 22, 21362.

[89] Huang, J. M.; Peng, R. X.; Xie, L. C.; Song, W.; Hong, L.; Chen, S. H.; Wei, Q.; Ge, Z. Y. J. Mater. Chem. A 2019, 7, 2646.

[90] Huang, J. M.; Xie, L. C.; Hong, L.; Wu, L. R.; Han, Y. F.; Yan, T. T.; Zhang, J. Q.; Zhu, L. Q.; Wei, Z. X.; Ge, Z. Y. Mater. Chem. Front. 2019, 3, 1244 .

[91] Cheon, Y. R.; Kim, Y. J.; Back, J. Y.; An, T. K.; Park, C. E.; Kim, Y. H. J. Mater. Chem. A 2014, 2, 16443.

[92] Jung, M.; Seo, D.; Kwak, K.; Kim, A.; Cha, W.; Kim, H.; Yoon, Y.; Ko, M. J.; Lee, D. K.; Kim, J. Y.; Hae, J. S.; Kim, B. Dyes Pigm. 2015, 115, 23.

[93] Feng, H. R.; Li, M. M.; Ni, W.; Kan, B.; Wang, Y. C.; Zhang, Y. M.; Zhang, H. T.; Wan, X. J.; Chen, Y. S. Sci. China-Chem. 2017, 60, 552.

[94] Je, H. I.; Hong, J.; Kwon, H. J.; Kim, N. Y.; Park, C. E.; Kwon, S. K.; An, T. K.; Kim, Y. H. Dyes Pigm. 2018, 157, 93.

[95] Hong, J.; Choi, J. Y.; Kim, K.; Lee, N. S.; Li, J.; Park, C. E.; An, T. K.; Kim, Y. H.; Kwon, S. K. Nanoscale 2019, 11, 1384.

[96] Abbas, Z.; Shin, J.; Atla, R.; Rasool, S.; Song, C. E.; Lee, H. K.;
Lee, S. K.; Shin, W. S.; So, W. W.; Kwon, S. K.; Kim, Y. H.; Lee, J. C. ACS Appl. Mater. Interfaces 2018, 10, 39107.

[97] Hong, J.; Sung, M. J.; Cha, H.; Park, C. E.; Durrant, J. R.; An, T. K.; Kim, Y. H.; Kwon, S. K. ACS Appl. Mater. Interfaces 2018, 10, 36037.

[98] Zhou, R. M.; Jiang, Z. Y.; Shi, Y. N.; Wu, Q.; Yang, C.; Zhang, J. Q.; Lu, K.; Wei, Z. X. Adv. Funct. Mater. 2020, 30, 2005426.

[99] Zhou, R. M.; Yang, C.; Zou, W.; Abdullah Adil, M.; Li, H.; Lv, M.; Huang, Z.; Lv, M.; Zhang, J.; Lu, K.; Wei, Z. J. Energy Chem. 2021, $52,228$.

[100] Ni, W.; Li, M. M.; Kan, B.; Liu, F.; Wan, X. J.; Zhang, Q.; Zhang, H. T.; Russell, T. P.; Chen, Y. S. Chem. Commun. 2016, 52, 465.

[101] Wang, W.; Chen, B. C.; Jiao, X. C.; Guo, J.; Sun, R.; Guo, J.; Min, J. Org. Electron. 2019, 70, 78.

[102] Zhang, H.; Wang, C. X.; Li, X.; Jing, J. L.; Sun, Y. Y.; Liu, Y. Q. Sol. Energy 2017, 157, 71 .

[103] Wang, Y. L.; Wang, Y.; Zhu, L.; Liu, H. Q.; Fang, J.; Guo, X.; Liu, F.; Tang, Z.; Zhang, M. J.; Li, Y. F. Energy Environ. Sci. 2020, 13, 1309.

[104] Yang, L. Y.; Zhang, S. Q.; He, C.; Zhang, J. Q.; Yao, H. F.; Yang, Y.; Zhang, Y.; Zhao, W. C.; Hou, J. H. J. Am. Chem. Soc. 2017, 139, 1958.

[105] Jiang, B. H.; Chen, C. P.; Liang, H. T.; Jeng, R. J.; Chien, W. C.; Yu, Y. Y. Dyes Pigm. 2020, 181, 108613.

[106] Yang, D.; Grott, S.; Jiang, X.; Wienhold, K. S.; Schwartzkopf, M.; Roth, S. V.; Mueller-Buschbaum, P. Small Methods 2020, 4, 2000418.

[107] Zhou, R. M.; Jiang, Z. Y.; Yang, C.; Yu, J. W.; Feng, J. R.; Adil, M. A.; Deng, D.; Zou, W. J.; Zhang, J. Q.; Lu, K.; Ma, W.; Gao, F.; Wei, Z. X. Nat. Commun. 2019, 10, 5393.

[108] Yang, D. B.; Wang, Y. M.; Sano, T.; Gao, F.; Sasabe, H.; Kido, J. J. Mater. Chem. A 2018, 6, 13918.

[109] Dai, S. X.; Zhan, X.W.; Acta Polym. Sin. 2017, 1706 (in Chinese). (代水星, 占肖卫, 高分子学报, 2017, 1706.)

(Cheng, B.) 